\title{
Trends in atmospheric evaporative demand in Great Britain using high-resolution meteorological data
}

\author{
Emma L. Robinson, Eleanor M. Blyth, Douglas B. Clark, Jon Finch, and Alison C. Rudd \\ Centre for Ecology and Hydrology, Maclean Building, Benson Lane, Crowmarsh Gifford, Wallingford, OX10 8BB, UK \\ Correspondence to: Emma L. Robinson (emrobi@ceh.ac.uk)
}

Received: 2 December 2015 - Discussion started: 27 January 2016

Revised: 7 February 2017 - Accepted: 9 February 2017 - Published: 28 February 2017

\begin{abstract}
Observations of climate are often available on very different spatial scales from observations of the natural environments and resources that are affected by climate change. In order to help bridge the gap between these scales using modelling, a new dataset of daily meteorological variables was created at $1 \mathrm{~km}$ resolution over Great Britain for the years 1961-2012, by interpolating coarser resolution climate data and including the effects of local topography. These variables were used to calculate atmospheric evaporative demand (AED) at the same spatial and temporal resolution. Two functions that represent AED were chosen: one is a standard form of potential evapotranspiration (PET) and the other is a derived PET measure used by hydrologists that includes the effect of water intercepted by the canopy (PETI). Temporal trends in these functions were calculated, with PET found to be increasing in all regions, and at an overall rate of $0.021 \pm 0.021 \mathrm{~mm} \mathrm{day}^{-1}$ decade $^{-1}$ in Great Britain. PETI was found to be increasing at a rate of $0.019 \pm 0.020 \mathrm{~mm} \mathrm{day}^{-1}$ decade $^{-1}$ in Great Britain, but this was not statistically significant. However, there was a trend in PETI in England of $0.023 \pm 0.023 \mathrm{~mm} \mathrm{day}^{-1}$ decade $^{-1}$. The trends were found to vary by season, with spring PET increasing by $0.043 \pm 0.019 \mathrm{~mm} \mathrm{day}^{-1}$ decade $^{-1}$ $\left(0.038 \pm 0.018 \mathrm{~mm} \mathrm{day}^{-1}\right.$ decade $^{-1}$ when the interception correction is included) in Great Britain, while there is no statistically significant trend in other seasons. The trends were attributed analytically to trends in the climate variables; the overall positive trend was predominantly driven by rising air temperature, although rising specific humidity had a negative effect on the trend. Recasting the analysis in terms of relative humidity revealed that the overall effect is that falling relative humidity causes the PET to rise. Increasing downward short- and longwave radiation made an overall
\end{abstract}

positive contribution to the PET trend, while decreasing wind speed made a negative contribution to the trend in PET. The trend in spring PET was particularly strong due to a strong decrease in relative humidity and increase in downward shortwave radiation in the spring.

\section{Introduction}

There are many studies showing the ways in which our living environment is changing over time: changing global temperatures (IPCC, 2013), radiation (Wild, 2009) and wind speeds (McVicar et al., 2012) can have significant impacts on ecosystems and human life (IPCC, 2014a). While there are overall global trends, the impacts can vary between regions (IPCC, 2014b). In the UK, wildlife surveys of both flora (Wood et al., 2015; Evans et al., 2008) and fauna (Pocock et al., 2015) show a shift in patterns and timing (Thackeray et al., 2010). In addition, the UK natural resources of freshwater (Watts et al., 2015), soils (Reynolds et al., 2013; Bellamy et al., 2005) and vegetation (Berry et al., 2002; Hickling et al., 2006; Norton et al., 2012) are changing. The UK is experiencing new environmental stresses on the land and water systems through changes in temperature and river flows (Crooks and Kay, 2015; Watts et al., 2015; Hannaford, 2015), which are part of a widespread global pattern of temperature increase and circulation changes (Watts et al., 2015).

To explain these changes in terms of climate drivers, there are several gridded meteorological datasets available at global and regional scales. Global datasets can be based on observations - for example the $0.5^{\circ}$ resolution Climate Research Unit time series 3.21 (CRU TS 3.21) data (Jones and Harris, 2013; Harris et al., 2014) - while some are based on 
global meteorological reanalyses bias-corrected to observations - for example the WATCH Forcing Data (WFD, $0.5^{\circ}$; Weedon et al., 2011), the WATCH Forcing Data methodology applied to ERA-Interim reanalysis product (WFDEI, $0.5^{\circ}$; Weedon et al., 2014) and the Princeton Global Meteorological Forcing Dataset $\left(0.25-1^{\circ}\right.$; Sheffield et al., 2006). At the regional scale in Great Britain (GB), there are datasets that are derived directly from observations - for example the Met Office Rainfall and Evaporation Calculation System (MORECS) dataset at $40 \mathrm{~km}$ resolution (Thompson et al., 1981; Hough and Jones, 1997; Field, 1983) and the UKCP09 observed climate data at $5 \mathrm{~km}$ resolution (Jenkins et al., 2008).

However, while regional observations of carbon, methane and water emissions from the land (Baldocchi et al., 1996), the vegetation cover (Morton et al., 2011) and soil properties (FAO/IIASA/ISRIC/ISS-CAS/JRC, 2012) are typically made at the finer landscape scale of 100 to $1000 \mathrm{~m}$, most of these long-term gridded meteorological datasets are only available at a relatively coarse resolution of a few tens of $\mathrm{km}$. These spatial scales may not be representative of the climate experienced by the flora and fauna being studied, and it has also been shown that input resolution can have a strong effect on the performance of hydrological models (Kay et al., 2015). In addition, the coarse temporal resolution of some datasets, for example the monthly CRU TS 3.21 data (Harris et al., 2014; Jones and Harris, 2013), can miss important sub-monthly extremes.

Regional studies are important to identify drivers and impacts of changing meteorology that may or may not be reflected in trends in global means. For example, in Canada (Vincent et al., 2015) and Europe (Fleig et al., 2015), highresolution meteorological data have been used to identify the impacts of changing circulation patterns, while in Australia wind speed data have been used to quantify the effects of global stilling in the region (McVicar et al., 2008). While there are datasets available at finer spatial and temporal resolutions for the UK (such as UKCP09; Jenkins et al., 2008), these often do not provide all the variables needed to identify the impacts of changing climate.

To address this, we have created a meteorological dataset for Great Britain at $1 \mathrm{~km}$ resolution: the Climate Hydrology and Ecology research Support System meteorology dataset for Great Britain (1961-2012) (CHESS-met; Robinson et al., 2015b). It is derived from the observation-based MORECS dataset (Thompson et al., 1981; Hough and Jones, 1997), and then downscaled using information about topography. This is augmented by an independent precipitation dataset - Gridded Estimates of daily and monthly Areal Rainfall for the United Kingdom (CEH-GEAR; Tanguy et al.; 2014; Keller et al., 2015) - along with variables from two global datasets - WFD and CRU TS 3.21 - to produce a comprehensive, observation-based, daily meteorological dataset at $1 \mathrm{~km} \times 1 \mathrm{~km}$ spatial resolution.
In order to understand the effect of meteorology on the water cycle, a key variable in hydrological modelling is the atmospheric evaporative demand (AED), which is determined by meteorological variables (Kay et al., 2013). It has been shown that water-resource and hydrological model results are largely driven by how this property is defined and used (Haddeland et al., 2011). The AED can be expressed in several ways - for instance the evaporation from a wet surface, from a well-watered but dry uniform vegetated cover, or from a hypothetical well-watered but dry version of the actual vegetation. Metrics such as the Palmer drought severity index (PDSI; Palmer, 1965) use potential evapotranspiration (PET) as an input to represent AED, while many hydrological models such as Climate and Land use Scenario Simulation in Catchments (CLASSIC; Crooks and Naden, 2007) or Gridto-Grid (G2G; Bell et al., 2009), which also require an input representing AED, use a distinct form of the PET which includes the intercepted water from rainfall (this is described later in the text) which we hereby name PETI. While hydrological models can make use of high-resolution topographic information and precipitation datasets, they are often driven with PET calculated at a coarser resolution (Bell et al., 2011, 2012; Kay et al., 2015). Therefore, we have also created a $1 \mathrm{~km} \times 1 \mathrm{~km}$ resolution dataset, the Climate Hydrology and Ecology research Support System Potential Evapotranspiration dataset for Great Britain (1961-2012) (CHESS-PE; Robinson et al., 2015a), consisting of estimates of PET and PETI, which can be used to run high-resolution hydrological models.

Other regional studies have created gridded estimates of AED in Austria (Haslinger and Bartsch, 2016) and Australia (Donohue et al., 2010). Regional studies of trends in AED have seen varied results, with increasing AED seen in Romania (Paltineanu et al., 2012), Serbia (Gocic and Trajkovic, 2013), Spain (Vicente-Serrano et al., 2014), some regions of China (Li and Zhou, 2014) and Iran (Azizzadeh and Javan, 2015; Hosseinzadeh Talaee et al., 2013; Tabari et al., 2012), decreasing AED in Northeast India (Jhajharia et al., 2012) and regions in China (Yin et al., 2009; Song et al., 2010; Shan et al., 2016; Zhao et al., 2015; Zhang et al., 2015; Lu et al., 2016) and regional variability in Australia (Donohue et al., 2010) and China (Li et al., 2015). In order to understand this variability, it is important to quantify the relative contributions of the changing meteorological variables to trends in AED, and regional studies often find different drivers of changing AED (see McVicar et al., 2012 for a review). Relative humidity has been shown to drive AED in the Canary Islands (Vicente-Serrano et al., 2016), wind speed and air temperature were shown to have nearly equal but opposite effects in Australia (Donohue et al., 2010), while in China sunshine hours (Li et al., 2015), wind speed (Yin et al., 2009) or a combination of the two (Lu et al., 2016) have been shown to drive trends. Rudd and Kay (2016) investigated projected changes in PET using a regional climate model, but little has been done to investigate historical trends of AED in the UK. 
The objectives of this paper are (i) to evaluate the trends in key meteorological variables in Great Britain over the years 1961-2012; (ii) to evaluate the AED in Great Britain over the same time period using PET; (iii) to investigate the effect of including interception in the formulation of PET called PETI; (iv) to evaluate trends in PET over the time period of interest; and (v) to attribute the trends in PET to trends in meteorological variables. To address these objectives, the paper is structured as follows. Section 2 presents the calculation of the meteorological variables. Section 3 presents the calculation of PET and PETI from the meteorological variables and assesses the difference between PET and PETI. In Sect. 4 the trends of the meteorological variables and AED are calculated and the trends in PET are attributed to trends in meteorological variables. In Sect. 5 the results are discussed and conclusions are presented in Sect. 6 .

\section{Calculation of meteorological variables}

The meteorological variables included in this new dataset (Robinson et al., 2015b) are daily mean values of air temperature, specific humidity, wind speed, downward longwave (LW) and shortwave (SW) radiation, precipitation and air pressure, plus daily temperature range (Table 1). These variables are important drivers of near-surface conditions, and, for instance, are the full set of variables required to drive the JULES land surface model (LSM) (Best et al., 2011; Clark et al., 2011), as well as other LSMs.

The data were derived primarily from MORECS, which is a long-term gridded dataset starting in 1961 and updated to the present (Thompson et al., 1981; Hough and Jones, 1997). It interpolates five variables from synoptic stations (daily mean values of air temperature, vapour pressure and wind speed, daily hours of bright sunshine and daily total precipitation) to a $40 \mathrm{~km} \times 40 \mathrm{~km}$ resolution grid aligned with the Ordnance Survey National Grid. There are currently 270 stations reporting in real time, while a further 170 report the daily readings on a monthly basis, but numbers have varied throughout the run. The algorithm interpolates a varying number of stations (up to nine) for each square, depending on data availability (Hough and Jones, 1997). The interpolation is such that the value in each grid square is the effective measurement of a station positioned at the centre of the square and at the grid square mean elevation, averaged from 00:00 to 00:00 GMT the next day. MORECS is a consistent, qualitycontrolled time series, which accounts for changing station coverage. The MORECS variables were used to derive the air temperature, specific humidity, wind speed, downward LW and SW radiation and air pressure in the new dataset. The WFD and CRU TS 3.21 datasets were used for surface air pressure and daily temperature range respectively, as they could not be calculated solely from MORECS. Additionally, precipitation was obtained from the CEH-GEAR data, which is a product directly interpolated to $1 \mathrm{~km}$ from the station data (Keller et al., 2015).

The spatial coverage of the dataset was determined by the spatial coverage of MORECS, which covers the majority of Great Britain, but excludes some coastal regions and islands at the $1 \mathrm{~km}$ scale. For most of these points, the interpolation was extended from the nearest MORECS squares, but some outlying islands (in particular Shetland and the Scilly Isles) were excluded when the entire island was further than $40 \mathrm{~km}$ from the nearest MORECS square.

\subsection{Air temperature}

Air temperature, $T_{\mathrm{a}}(\mathrm{K})$, was derived from the MORECS air temperature. The MORECS air temperature was reduced to mean sea level, using a lapse rate of $-0.006 \mathrm{~K} \mathrm{~m}^{-1}$ (Hough and Jones, 1997). A bicubic spline was used to interpolate from $40 \mathrm{~km}$ resolution to $1 \mathrm{~km}$ resolution, then the temperatures were adjusted to the elevation of each $1 \mathrm{~km}$ square using the same lapse rate. The $1 \mathrm{~km}$ resolution elevation data used were aggregated from the Integrated Hydrological Digital Terrain Model (IHDTM) - a $50 \mathrm{~m}$ resolution digital terrain model (Morris and Flavin, 1990).

\subsection{Specific humidity}

Specific humidity, $q_{\mathrm{a}}\left(\mathrm{kg} \mathrm{kg}^{-1}\right)$, was derived from the MORECS vapour pressure, $e_{\mathrm{M}}(\mathrm{Pa})$, which was first reduced to mean sea level, using the equation

$e_{\text {sea }}=e_{\mathrm{M}}\left(1-\frac{L_{\mathrm{e}}}{100} h_{\mathrm{M}}\right)$,

where $L_{\mathrm{e}}$ is the lapse rate of $-0.025 \% \mathrm{~m}^{-1}$ and $h$ is the elevation of the MORECS square (Thompson et al., 1981). The actual lapse rate of humidity will, in general, vary according to atmospheric conditions. However, calculating this would require more detailed information than is available in the input data used. Any method of calculating the variation of specific humidity with height will involve several assumptions, but the method used here is well-established and is used by the Met Office in calculating MORECS (Thompson et al., 1981). The value of the vapour pressure lapse rate is chosen to keep relative humidity approximately constant with altitude, rather than assuming that the vapour pressure itself is constant.

A bicubic spline was used to interpolate vapour pressure to $1 \mathrm{~km}$ resolution then the values were adjusted to the $1 \mathrm{~km}$ resolution elevation using the IHDTM elevations and using the same lapse rate, such that

$e=e_{\text {sea }, 1 \mathrm{~km}}\left(1+\frac{L_{\mathrm{e}}}{100} h_{1 \mathrm{~km}}\right)$,

where $e_{\text {sea, } 1 \mathrm{~km}}$ is the sea-level vapour pressure at $1 \mathrm{~km}$ resolution and $h_{1} \mathrm{~km}$ is the $1 \mathrm{~km}$ resolution elevation. 
Table 1. Description of input meteorological variables. n/a: not applicable.

\begin{tabular}{|c|c|c|c|c|}
\hline $\begin{array}{l}\text { Variable } \\
\text { (units) }\end{array}$ & Source data & Ancillary files & Assumptions & Height \\
\hline $\begin{array}{l}\text { Air temperature } \\
(\mathrm{K})\end{array}$ & $\begin{array}{l}\text { MORECS air } \\
\text { temperature }\end{array}$ & IHDTM elevation & $\begin{array}{l}\text { Lapsed to IHDTM } \\
\text { elevation }\end{array}$ & $1.2 \mathrm{~m}$ \\
\hline $\begin{array}{l}\text { Specific } \\
\text { humidity } \\
\left(\mathrm{kg} \mathrm{kg}^{-1}\right)\end{array}$ & $\begin{array}{l}\text { MORECS vapour } \\
\text { pressure }\end{array}$ & IHDTM elevation & $\begin{array}{l}\text { Lapsed to IHDTM } \\
\text { elevation } \\
\text { Constant air } \\
\text { pressure = } \\
100 \mathrm{kPa}\end{array}$ & $1.2 \mathrm{~m}$ \\
\hline $\begin{array}{l}\text { Downward LW } \\
\text { radiation } \\
\left(\mathrm{W} \mathrm{m}^{-2}\right)\end{array}$ & $\begin{array}{l}\text { MORECS air } \\
\text { temperature, } \\
\text { vapour pressure, } \\
\text { sunshine hours }\end{array}$ & IHDTM elevation & $\begin{array}{l}\text { Constant cloud } \\
\text { base height }\end{array}$ & $1.2 \mathrm{~m}$ \\
\hline $\begin{array}{l}\text { Downward SW } \\
\text { radiation } \\
\left(\mathrm{W} \mathrm{m}^{-2}\right)\end{array}$ & $\begin{array}{l}\text { MORECS sunshine } \\
\text { hours }\end{array}$ & $\begin{array}{l}\text { IHDTM elevation } \\
\text { Spatially varying } \\
\text { aerosol correction }\end{array}$ & $\begin{array}{l}\text { No time-varying } \\
\text { aerosol correction }\end{array}$ & $1.2 \mathrm{~m}$ \\
\hline $\begin{array}{l}\text { Wind speed } \\
\left(\mathrm{m} \mathrm{s}^{-1}\right)\end{array}$ & $\begin{array}{l}\text { MORECS wind } \\
\text { speed }\end{array}$ & $\begin{array}{l}\text { ETSU average } \\
\text { wind speeds }\end{array}$ & $\begin{array}{l}\text { Wind speed } \\
\text { correction is } \\
\text { constant }\end{array}$ & $10 \mathrm{~m}$ \\
\hline $\begin{array}{l}\text { Precipitation } \\
\left(\mathrm{kg} \mathrm{m}^{-2} \mathrm{~s}^{-1}\right)\end{array}$ & $\begin{array}{l}\text { CEH-GEAR } \\
\text { precipitation }\end{array}$ & - & $\begin{array}{l}\text { No } \\
\text { transformations } \\
\text { performed }\end{array}$ & $\mathrm{n} / \mathrm{a}$ \\
\hline $\begin{array}{l}\text { Daily } \\
\text { temperature } \\
\text { range } \\
(\mathrm{K})\end{array}$ & $\begin{array}{l}\text { CRU TS } 3.21 \text { daily } \\
\text { temperature range }\end{array}$ & - & $\begin{array}{l}\text { No spatial } \\
\text { interpolation from } \\
0.5^{\circ} \text { resolution. } \\
\text { No temporal } \\
\text { interpolation } \\
\text { (constant values } \\
\text { for each month) }\end{array}$ & $1.2 \mathrm{~m}$ \\
\hline $\begin{array}{l}\text { Surface air } \\
\text { pressure } \\
(\mathrm{Pa})\end{array}$ & WFD air pressure & IHDTM elevation & $\begin{array}{l}\text { Mean monthly } \\
\text { values from WFD } \\
\text { used (each year } \\
\text { has same values). } \\
\text { Lapsed to IHDTM } \\
\text { elevation. No } \\
\text { temporal } \\
\text { interpolation } \\
\text { (constant values } \\
\text { for each month) }\end{array}$ & $\mathrm{n} / \mathrm{a}$ \\
\hline
\end{tabular}

Finally the specific humidity was calculated, using

$q_{\mathrm{a}}=\frac{\epsilon e}{p_{*}-(1-\epsilon) e}$,

where $e$ is the vapour pressure (Pa) and $\epsilon=0.622$ is the mass ratio of water to dry air (Gill, 1982). The air pressure, $p_{*}$, in this calculation was assumed to have a constant value of $100000 \mathrm{~Pa}$ because this was prescribed in the computer code. It would be better to use a varying air pressure, as calculated in Sect. 2.8, but this makes a negligible difference (of a few percent) to the calculated specific humidity, and to the PET and PETI calculated in Sect. 3, and a constant $p_{*}$ was retained.

\subsection{Downward shortwave radiation}

Downward SW radiation, $S_{\mathrm{d}}\left(\mathrm{W} \mathrm{m}^{-2}\right)$, was derived from the MORECS hours of bright sunshine (defined as the total number of hours in a day for which solar irradiation exceeds $120 \mathrm{~W} \mathrm{~m}^{-2}$; WMO, 2013). The value calculated is the mean $\mathrm{SW}$ radiation over $24 \mathrm{~h}$. The sunshine hours were used to calculate the cloud cover factor, $C_{\mathrm{f}}=n / N$, where $n$ is the num- 
ber of hours of bright sunshine in a day, and $N$ is the total number of hours between sunrise and sunset (Marthews et al., 2011). The cloud cover factor was interpolated to $1 \mathrm{~km}$ resolution using a bicubic spline. The downward SW solar radiation for a horizontal plane at the Earth's surface was then calculated using the solar angle equations of Iqbal (1983) and a form of the Ångström-Prescott equation which relates hours of bright sunshine to solar irradiance (Ångström, 1918; Prescott, 1940), with empirical coefficients calculated by Cowley (1978). They vary spatially and seasonally and effectively account for reduction of irradiance with increasing solar zenith angle, as well as implicitly accounting for spatially and seasonally varying aerosol effects. However, they do not vary interannually and thus do not explicitly include long-term trends in aerosol concentration.

The downward SW radiation was then corrected for the average inclination and aspect of the surface, assuming that only the direct beam radiation is a function of the inclination and that the diffuse radiation is homogeneous. It was also assumed that the cloud cover is the dominant factor in determining the diffuse fraction (Muneer and Munawwar, 2006). The aspect and inclination were calculated using the IHDTM elevation at $50 \mathrm{~m}$ resolution, following the method of Horn (1981), and were then aggregated to $1 \mathrm{~km}$ resolution. The top of atmosphere flux for horizontal and inclined surfaces was calculated following Allen et al. (2006) and the ratio used to scale the direct beam radiation.

\subsection{Downward longwave radiation}

Downward LW radiation, $L_{\mathrm{d}}\left(\mathrm{W} \mathrm{m}^{-2}\right)$, was derived from the $1 \mathrm{~km}$ resolution air temperature (Sect. 2.1), vapour pressure (Sect. 2.2) and cloud cover factor (Sect. 2.3). The downward LW radiation for clear-sky conditions was calculated as a function of air temperature and precipitable water using the method of Dilley and O'Brien (1998), with precipitable water calculated from air temperature and humidity following Prata (1996). The additional component due to cloud cover was calculated using the equations of Kimball et al. (1982), assuming a constant cloud base height of $1000 \mathrm{~m}$.

\subsection{Wind speed}

The wind speed at a height of $10 \mathrm{~m}, u_{10}\left(\mathrm{~m} \mathrm{~s}^{-1}\right)$, was derived from the MORECS $10 \mathrm{~m}$ wind speed, which were interpolated to $1 \mathrm{~km}$ resolution using a bicubic spline and adjusted for topography using a $1 \mathrm{~km}$ resolution dataset of mean wind speeds produced by the UK Energy Technology Support Unit (ETSU; Newton and Burch, 1985; Burch and Ravenscroft, 1992). This used Numerical Objective Analysis Boundary Layer (NOABL) methodology combined with station wind measurements over the period 1975-1984 to produce a map of mean wind speed over the UK. To calculate the topographic correction, the ETSU wind speed was aggregated to $40 \mathrm{~km}$ resolution, then the difference between each $1 \mathrm{~km}$ value and the corresponding $40 \mathrm{~km}$ mean found. This difference was added to the interpolated daily wind speed. In cases where this would result in a negative wind speed, the wind speed was set to zero.

\subsection{Precipitation}

Precipitation rate, $P\left(\mathrm{~kg} \mathrm{~m}^{-2} \mathrm{~s}^{-1}\right)$, is taken from the daily CEH-GEAR dataset (Tanguy et al., 2014; Keller et al., 2015), scaled to the appropriate units. The CEH-GEAR methodology uses natural neighbour interpolation (Gold, 1989) to interpolate synoptic station data to a $1 \mathrm{~km}$ resolution gridded daily dataset of the estimated precipitation in $24 \mathrm{~h}$ between 09:00 and 09:00 GMT the next day.

\subsection{Daily temperature range}

Daily temperature range (DTR), $D_{T}(\mathrm{~K})$, was obtained from the CRU TS 3.21 monthly mean daily temperature range estimates on a $0.5^{\circ}$ latitude $\times 0.5^{\circ}$ longitude grid, which is interpolated from monthly climate observations (Harris et al., 2014; Jones and Harris, 2013). There is no standard way to correct DTR for elevation, so these data were reprojected to the $1 \mathrm{~km}$ grid with no interpolation and the monthly mean used to populate the daily values in each month. Although DTR is not required in the calculation of AED, it is a required input of the JULES LSM, in order to run at a sub-daily time step with daily input data.

\subsection{Surface air pressure}

Surface air pressure, $p_{*}(\mathrm{~Pa})$, was derived from the WFD, an observation-corrected reanalysis product, which provides 3-hourly meteorological data for $1958-2001$ on a $0.5^{\circ}$ latitude $\times 0.5^{\circ}$ longitude resolution grid (Weedon et al., 2011). Mean monthly values of WFD surface air pressure and air temperature were calculated for each $0.5^{\circ}$ grid box over the years 1961-2001. These were reprojected to the $1 \mathrm{~km}$ grid with no interpolation, then the lapse rate of air temperature (Sect. 2.1) used to calculate the integral of the hypsometric equation (Shuttleworth, 2012), in order to obtain the air pressure at the elevation of each $1 \mathrm{~km}$ grid. The mean monthly values were used to populate the daily values in the full dataset, thus the surface air pressure in the new dataset does not vary interannually, but does vary seasonally. This is reasonable as the trend in surface air pressure in the WFD is negligible (Weedon et al., 2011).

\subsection{Spatial and seasonal patterns of meteorological variables}

Long-term mean values of the meteorological variables were calculated for each $1 \mathrm{~km}$ square over the whole dataset, covering the years 1961-2012 (Fig. 1). Four sub-regions of interest were defined (Fig. 2); three of these regions correspond to nations (England, Wales and Scotland), while the fourth is 

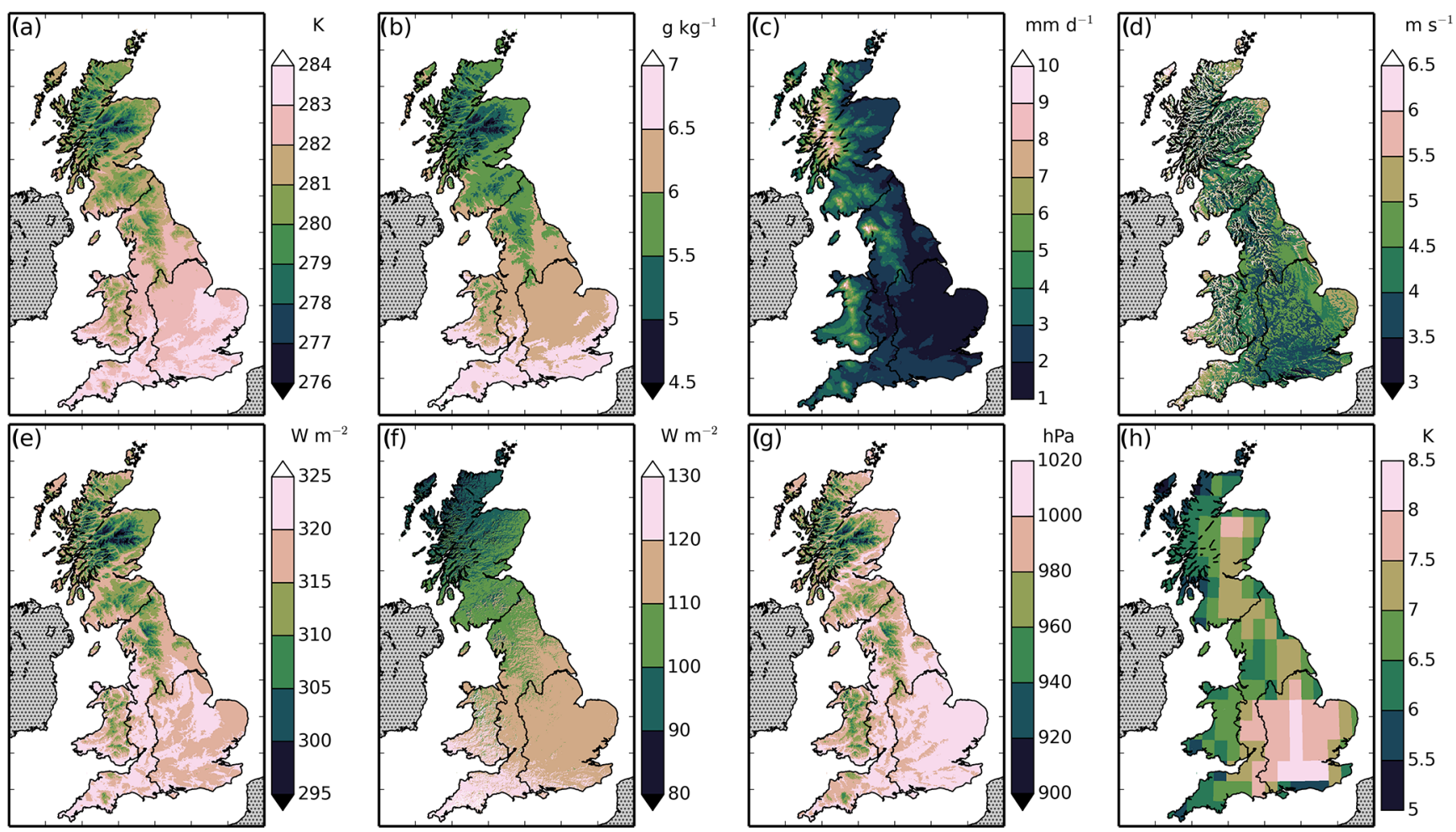

Figure 1. Means of the meteorological variables over the years 1961-2012. The variables are (a) $1.2 \mathrm{~m}$ air temperature, (b) $1.2 \mathrm{~m}$ specific humidity, (c) precipitation, (d) $10 \mathrm{~m}$ wind speed, (e) downward LW radiation, (f) downward SW radiation, (g) surface air pressure, and (h) daily air temperature range.

the "English lowlands", a subset of England, covering Southcentral and Southeast England, East Anglia and the East Midlands (Folland et al., 2015). Mean monthly climatologies were calculated over the whole of Great Britain (GB), and over these four regions of interest (Fig. 3).

The maps clearly show the effect of topography on the variables (Fig. 1), with an inverse correlation between elevation and temperature, specific humidity, downward LW radiation and surface air pressure and a positive correlation with wind speed. The precipitation has an east-west gradient due to prevailing weather systems and orography. The fine-scale structure of the downward SW radiation is due to the aspect and elevation of each grid cell, with more spatial variability in areas with more varying terrain. As no topographic correction has been applied to DTR, it varies only on a larger spatial scale. Although specific humidity is inversely proportional to elevation, relative humidity is not, as the saturated specific humidity will also be inversely proportional to elevation due to the decrease in temperature with height. The strong correlation between wind speed and elevation means that it is very variable over short spatial scales, particularly in Scotland.

The mean monthly climatologies (Fig. 3) demonstrate the differences between the regions, with Scotland generally having lower temperatures and more precipitation than the average, and England (particularly the English lowlands) being warmer and drier.

\subsection{Validation of meteorology}

The precipitation dataset, CEH-GEAR, has previously been validated against observations (Keller et al., 2015). Other studies discuss the uncertainties in the CRU TS 3.21 daily temperature range data (Harris et al., 2014) and WFDEI air pressure data (Weedon et al., 2014).

For the other variables, the MORECS dataset is ultimately derived from the synoptic stations around the UK which represent most of the available observed meteorological data for the country. The only way to validate the gridded meteorology presented here is to compare it to independently observed data, which are available at a few sites where meteorological measurement stations that are not part of the synoptic network are located. Here we carry out a validation exercise with data from four sites from the UK, which have meteorological measurements available for between 5 and 10 years. Details of the sites and data are in Appendix A. Figure 4 shows the comparison of dataset air temperature with the observed air temperature at each of the four sites. This shows a strong correlation $\left(r^{2}\right.$ between 0.94 and 0.97$)$ between the dataset and the observations. Figure 5 shows the mean monthly climatology calculated from both the dataset 


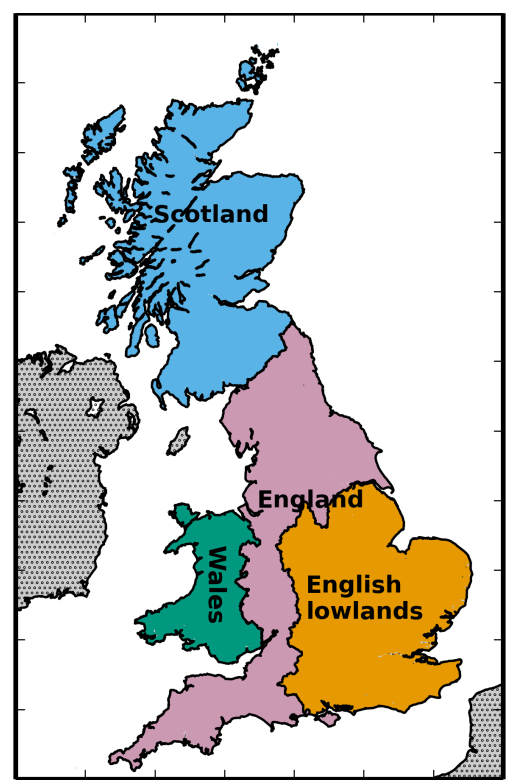

Figure 2. The regions used to calculate the area means. The English lowlands are a sub-region of England. England, Scotland and Wales together form the fifth region, Great Britain.

and from the observations (only for times for which observations were available) and demonstrates that the dataset successfully captures the seasonal cycle. This has been repeated for downward SW radiation and for an estimate of the mixing ratio of water vapour, $10 \mathrm{~m}$ wind speed and surface air pressure (Appendix A). The air temperature, downward SW radiation and mixing ratio all have high correlations and represent the seasonal cycle well. The downward SW is overestimated at Auchencorth Moss, which may be due to local factors (e.g. shading, or the siting of the station within the grid square). The wind speed is overestimated by the derived dataset at two sites, which is likely to be due to land cover effects. The modelling which produced the ETSU dataset uses topography but not land cover (Burch and Ravenscroft, 1992; Newton and Burch, 1985), so at sites with tall vegetation the wind speed is likely to be less than the modelled value. The air pressure has a low correlation because the dataset contains a mean monthly climatological value. However, the mean bias is low and the RMSE is small, confirming that it is reasonable to use a climatological value in place of daily data.

\section{Calculation of potential evapotranspiration (PET)}

There are several ways to assess the evaporative demand of the atmosphere. Pan evaporation can be modelled using the Pen-Pan model (Rotstayn et al., 2006), or open-water evaporation can be modelled with the Penman equation (Penman, 1948). However, neither of these account for the fact that in general the evaporation is occurring from a vegetated sur- face. A widely used model is the Penman-Monteith PET, $E_{\mathrm{P}}$ (mm day ${ }^{-1}$, equivalent to $\mathrm{kg} \mathrm{m}^{-2} \mathrm{day}^{-1}$ ), which is a physically based formulation of AED (Monteith, 1965), including the effect of stomatal resistance. It provides an estimate of AED dependent on the atmospheric conditions but allowing for the fact that the water is evaporating through the surface of leaves and thus the resistance is higher. It can be calculated from the daily meteorological variables using the equation

$E_{\mathrm{P}}=\frac{t_{\mathrm{d}}}{\lambda} \frac{\Delta A+\frac{c_{\mathrm{p}} \rho_{\mathrm{a}}}{r_{\mathrm{a}}}\left(q_{\mathrm{s}}-q_{\mathrm{a}}\right)}{\Delta+\gamma\left(1+\frac{r_{\mathrm{s}}}{r_{\mathrm{a}}}\right)}$,

where $t_{\mathrm{d}}=86400 \mathrm{~s} \mathrm{day}^{-1}$ is the length of a day, $\lambda=2.5 \times 10^{6} \mathrm{~J} \mathrm{~kg}^{-1}$ is the latent heat of evaporation, $q_{\mathrm{s}}$ is saturated specific humidity $\left(\mathrm{kg} \mathrm{kg}^{-1}\right), \Delta$ is the gradient of saturated specific humidity with respect to temperature $\left(\mathrm{kg} \mathrm{kg}^{-1} \mathrm{~K}^{-1}\right), A$ is the available energy $\left(\mathrm{W} \mathrm{m}^{-2}\right)$, $c_{\mathrm{p}}=1010 \mathrm{~J} \mathrm{~kg}^{-1} \mathrm{~K}^{-1}$ is the specific heat capacity of air, $\rho_{\mathrm{a}}$ is the density of air $\left(\mathrm{kg} \mathrm{m}^{-3}\right), q_{\mathrm{a}}$ is specific humidity $\left(\mathrm{kg} \mathrm{kg}^{-1}\right), \gamma=0.004 \mathrm{~K}^{-1}$ is the psychrometric constant, $r_{\mathrm{s}}$ is stomatal resistance $\left(\mathrm{s} \mathrm{m}^{-1}\right)$ and $r_{\mathrm{a}}$ is aerodynamic resistance $\left(\mathrm{s} \mathrm{m}^{-1}\right)$ (Stewart, 1989).

The saturated specific humidity, $q_{\mathrm{s}}\left(\mathrm{kg} \mathrm{kg}^{-1}\right)$, is calculated from saturated vapour pressure, $e_{\mathrm{s}}(\mathrm{Pa})$, using Eq. (3). The saturated vapour pressure is calculated using an empirical fit to air temperature

$e_{\mathrm{s}}=p_{\mathrm{sp}} \exp \left(\sum_{i=1}^{4} a_{i}\left(1-\frac{T_{\mathrm{sp}}}{T_{\mathrm{a}}}\right)^{i}\right)$,

where $p_{\mathrm{sp}}=101325 \mathrm{~Pa}$ is the steam point pressure, $T_{\mathrm{sp}}=373.15 \mathrm{~K}$ is the steam point temperature and $a=(13.3185,-1.9760,-0.6445,-0.1299)$ are empirical coefficients (Richards, 1971).

The derivative of the saturated specific humidity with respect to temperature, $\Delta\left(\mathrm{kg} \mathrm{kg}^{-1} \mathrm{~K}^{-1}\right)$, is therefore

$\Delta=\frac{T_{\mathrm{sp}}}{T_{\mathrm{a}}^{2}} \frac{p_{*} q_{\mathrm{s}}}{p_{*}-(1-\epsilon) e_{\mathrm{s}}} \sum_{i=1}^{4} i a_{i}\left(1-\frac{T_{\mathrm{sp}}}{T_{\mathrm{a}}}\right)^{i-1}$,

where the air pressure used is the spatially varying air pressure calculated in Sect. 2.8.

The available energy, $A\left(\mathrm{~W} \mathrm{~m}^{-2}\right)$, is the energy balance of the surface,

$A=R_{\mathrm{n}}-G$,

where $R_{\mathrm{n}}$ is the net radiation ( $\mathrm{W} \mathrm{m}^{-2}$ ) and $G$ is the soil heat flux $\left(\mathrm{W} \mathrm{m}^{-2}\right)$. The net soil heat flux is negligible at the daily timescale (Allen et al., 1998), so the available energy is equal to the net radiation, such that

$A=(1-\alpha) S_{\mathrm{d}}+\varepsilon\left(L_{\mathrm{d}}-\sigma T_{*}^{4}\right)$,

where $\sigma$ is the Stefan-Boltzmann constant, $\alpha$ is the albedo and $\varepsilon$ the emissivity of the surface and $T_{*}$ is the surface temperature (Shuttleworth, 2012). For this study we make the 

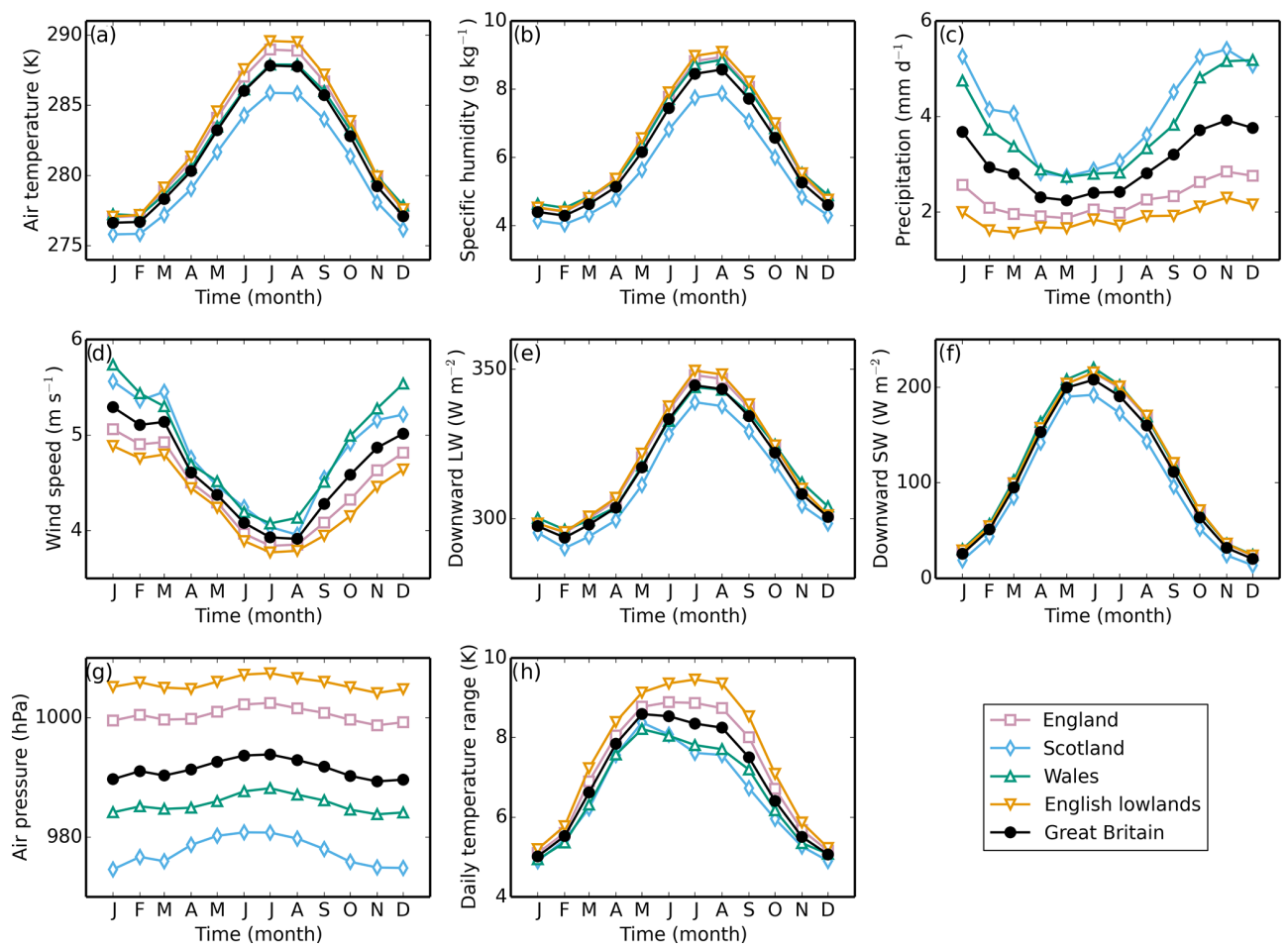

Figure 3. Mean monthly climatology of meteorological variables, (a) $1.2 \mathrm{~m}$ air temperature, (b) $1.2 \mathrm{~m}$ specific humidity, (c) precipitation, (d) $10 \mathrm{~m}$ wind speed, (e) downward LW radiation, (f) downward SW radiation, (g) surface air pressure, and (h) daily air temperature range, for five different regions of Great Britain, calculated over the years 1961-2012.
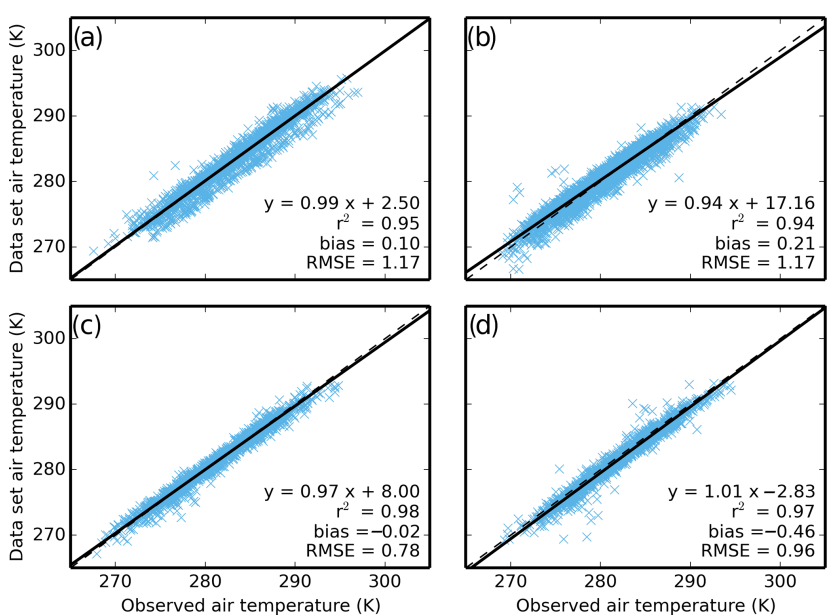

Figure 4. Plot of dataset air temperature against daily mean observed air temperature at four sites. The dashed line shows the one to one line, while the solid line shows the linear regression, the equation of which is shown in the lower right of each plot, along with the $r^{2}$ value, the mean bias and the RMSE. The sites are (a) Alice Holt, (b) Griffin Forest, (c) Auchencorth Moss, and (d) Easter Bush.

simplifying assumption that the surface temperature is approximately equal to the air temperature, $T_{\mathrm{a}}$ and use the latter in Eq. (8).
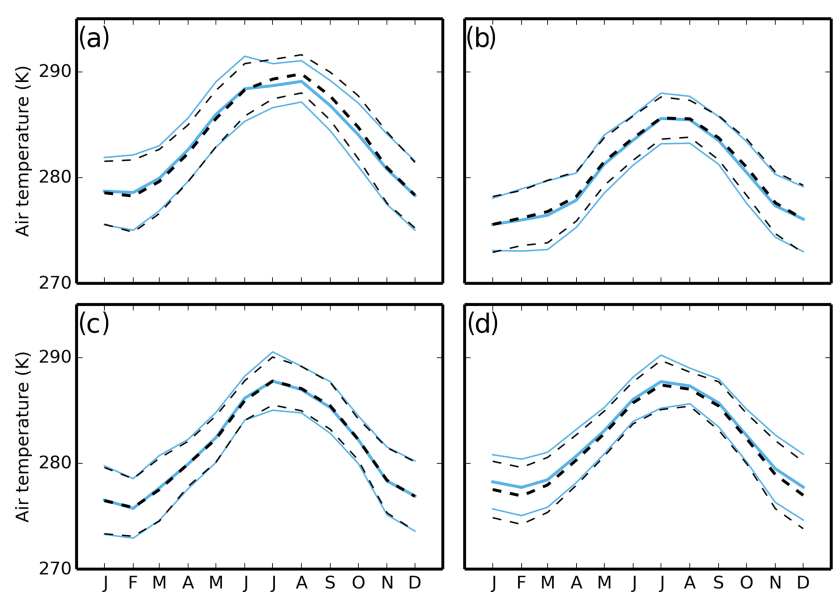

Figure 5. Mean monthly climatology of the dataset (black, dashed lines) and observed (blue, solid lines) air temperatures, calculated for the period of observations. The thicker lines show the means, while the thinner lines show the standard errors on each measurement. Sites as in Fig. 4.

The air density, $\rho_{\mathrm{a}}\left(\mathrm{kg} \mathrm{m}^{-3}\right)$, is a function of air pressure and temperature,

$\rho_{\mathrm{a}}=\frac{p_{*}}{r T_{\mathrm{a}}}$, 
where $r=287.05 \mathrm{~J} \mathrm{~kg}^{-1} \mathrm{~K}^{-1}$ is the gas constant of air and the air pressure used is the spatially varying air pressure calculated in Sect. 2.8.

The stomatal and aerodynamic resistances are strongly dependent on land cover due to differences in roughness length and physiological constraints on transpiration of different vegetation types. In addition, the albedo and emissivity are also dependent on the land cover. In order to investigate the effect of meteorology on AED, as distinct from land use effects, the PET was calculated for a single land cover type over the whole of the domain. If necessary, this can be adjusted to give an estimate of PET specific to the local land cover, for example using regression relationships (Crooks and Naden, 2007). As a standard, the Food and Agriculture Organization of the United Nations (FAO) calculate reference crop evaporation for a hypothetical reference crop, which corresponds to a well-watered grass (Allen et al., 1998). Following this, the PET in the current study was calculated for a reference crop of $0.12 \mathrm{~m}$ height, with constant stomatal resistance, $r_{\mathrm{s}}=70.0 \mathrm{~s} \mathrm{~m}^{-1}$, an albedo of 0.23 and emissivity of 0.92 over the whole of Great Britain. This study therefore neglects the effect of land use on evaporation, which could be investigated in future by calculating PET for different land surface types, with different coverage for each year of the dataset.

In general, aerodynamic resistance is a function of wind speed and canopy height. Following Allen et al. (1998), the aerodynamic resistance, $r_{\mathrm{a}}\left(\mathrm{s} \mathrm{m}^{-1}\right)$, of a reference crop of $0.12 \mathrm{~m}$ height is a function of the $10 \mathrm{~m}$ wind speed

$r_{\mathrm{a}}=\frac{278}{u_{10}}$.

Note that, since the wind speed is likely to be biased high at sites with tall vegetation (Sect. 2.10), this implies that the aerodynamic resistance is likely to be biased low, leading to an overestimate of PET. However, the estimate of PET here is for a reference crop over the whole of the dataset, and does not consider the effect of tall vegetation, so the wind speed is appropriate.

Thus the PET is a function of six of the meteorological variables: air temperature, specific humidity, downward LW and SW radiation, wind speed and surface air pressure.

To explore the role of the different meteorological variables in the AED, it is helpful to split the radiative component (the first part of the numerator in Eq. 4) from the wind component (the second part). Formally, this is defined as follows (Doorenbos, 1977):

the radiative component, $E_{\mathrm{PR}}$,

$E_{\mathrm{PR}}=\frac{t_{\mathrm{d}}}{\lambda} \frac{\Delta A}{\Delta+\gamma\left(1+\frac{r_{\mathrm{s}}}{r_{\mathrm{a}}}\right)}$, and the aerodynamic component, $E_{\mathrm{PA}}$,

$E_{\mathrm{PA}}=\frac{t_{\mathrm{d}}}{\lambda} \frac{\frac{c_{\mathrm{p}} \rho_{\mathrm{a}}}{r_{\mathrm{a}}}\left(q_{\mathrm{s}}-q_{\mathrm{a}}\right)}{\Delta+\gamma\left(1+\frac{r_{\mathrm{s}}}{r_{\mathrm{a}}}\right)}$,

such that $E_{\mathrm{P}}=E_{\mathrm{PR}}+E_{\mathrm{PA}}$.

\subsection{Potential evapotranspiration with interception (PETI)}

When rain falls, water is intercepted by the canopy. The evaporation of this water is not constrained by stomatal resistance but is subject to the same aerodynamic resistance as transpiration (Shuttleworth, 2012). At the same time, transpiration is inhibited in a wet canopy. Suppression of transpiration is well observed both by comparing eddy-covariance fluxes and observations of sap flow (Kume et al., 2006; Moors, 2012), and by observing stomatal and photosynthesis response to wetting (Ishibashi and Terashima, 1995). For plants which have at least some of their stomata on the upper surface of the leaves, this can be due to water directly blocking the stomata. However, in GB most plants have stomata only on the underside of the leaves, so the transpiration is inhibited by other mechanisms.

Physically, the suppression may be due to the fact that energy is used in evaporating the intercepted water, so less is available for transpiration or that the increased humidity of the air decreases the evaporative demand (Bosveld and Bouten, 2003). It may also be due to the presence of water on the leaf surface causing stomatal closure through physiological reactions, which can be observed even when the stomata are on the underside of a leaf and the water is lying on the upper side (Ishibashi and Terashima, 1995).

In the short term after a rain event, potential water losses due to evaporation may be underestimated if only potential transpiration is calculated, and therefore overall rates underestimated. As transpiration is inhibited over the wet fraction of the canopy (Ward and Robinson, 2000), the PET over a grid box will be a linear combination of the potential interception and potential transpiration, each weighted by the fraction of the canopy that is wet or dry. This can be accounted for by introducing an interception term to the calculation of PET, giving PETI. This is modelled as an interception store, which is (partially) filled by rainfall, proportionally inhibiting the transpiration. As the interception store dries, the relative contribution of interception is decreased and the transpiration increases. In this dataset, this correction is applied on days with precipitation, while on days without precipitation the potential is equal to the PET defined in Eq. (4). Although an unconventional definition of PET, a similar interception correction is applied to the PET provided at $40 \mathrm{~km}$ resolution by MORECS (Thompson et al., 1981) which is used widely by hydrologists.

This method implicitly assumes that the water is liquid, however snow lying on the canopy will also inhibit transpi- 
ration, and will be depleted by melting as well as by sublimation. The rates may be slower, and the snow may stay on the canopy for longer than 1 day. However, the difference of accounting for canopy snow as distinct from canopy water will have a small effect on large-scale averages, as the number of days with snow cover in GB is relatively low, and they occur during winter when the PET is small.

The PETI is a weighted sum of the PET, $E_{\mathrm{P}}$, (as calculated in Eq. 2) and potential interception, $E_{\mathrm{I}}$, which is calculated by substituting zero stomatal resistance, $r_{\mathrm{s}}=0 \mathrm{~s} \mathrm{~m}^{-1}$, into Eq. (4). To calculate the relative proportions of interception and transpiration, it is assumed that the wet fraction of the canopy is proportional to the amount of water in the interception store. The interception store, $S_{\mathrm{I}}\left(\mathrm{kg} \mathrm{m}^{-2}\right)$, decreases through the day according to an exponential dry down (Rutter et al., 1971), such that

$S_{\mathrm{I}}(t)=S_{0} e^{-\frac{E_{\mathrm{I}}}{S_{\mathrm{tot}}} t}$,

where $E_{\mathrm{I}}$ is the potential interception, $S_{\text {tot }}$ is the total capacity of the interception store $\left(\mathrm{kg} \mathrm{m}^{-2}\right), S_{0}$ is the precipitation that is intercepted by the canopy $\left(\mathrm{kg} \mathrm{m}^{-2}\right)$ and $t$ is the time (in days) since a rain event. We assume that the interception component is only significant on the day in which rainfall occurs, and that it is negligible on subsequent days, so the calculation is only carried out for days of non-zero rainfall. Thus $t$ is a positive fraction between zero and one.

The total capacity of the interception store is calculated following Best et al. (2011), such that

$S_{\text {tot }}=0.5+0.05 \Lambda$

where $\Lambda$ is the leaf area index (LAI). For the FAO standard grass land cover the LAI is 2.88 (Allen et al., 1998). The fraction of precipitation intercepted by the canopy is also found following Best et al. (2011), assuming that precipitation lasts for an average of $3 \mathrm{~h}$.

The wet fraction of the canopy, $C_{\text {wet }}$, is proportional to the store size, such that

$C_{\text {wet }}(t)=\frac{S(t)}{S_{\text {tot }}}$.

The total PETI is the sum of the interception from the wet canopy and the transpiration from the dry canopy,

$E_{\mathrm{PI}}(t)=E_{\mathrm{I}} C_{\text {wet }}(t)+E_{\mathrm{P}}\left(1-C_{\mathrm{wet}}(t)\right)$.

This is integrated over 1 day (from $t=0$ to $t=1$ ) to find the total PETI, $E_{\mathrm{PI}}\left(\mathrm{mm} \mathrm{day}^{-1}\right)$, to be

$E_{\mathrm{PI}}=S_{0}\left(1-e^{-\frac{E_{\mathrm{I}}}{S_{\mathrm{tot}}}}\right)+E_{\mathrm{P}}\left(1-\frac{S_{0}}{E_{\mathrm{I}}}\left(1-e^{-\frac{E_{\mathrm{I}}}{S_{\mathrm{tot}}}}\right)\right)$.

This calculation is only carried out for days on which rainfall occurs. On subsequent days it is assumed that the canopy has sufficiently dried out that the interception component is zero.

The PETI is a function of the same six meteorological variables as the PET, plus the precipitation.
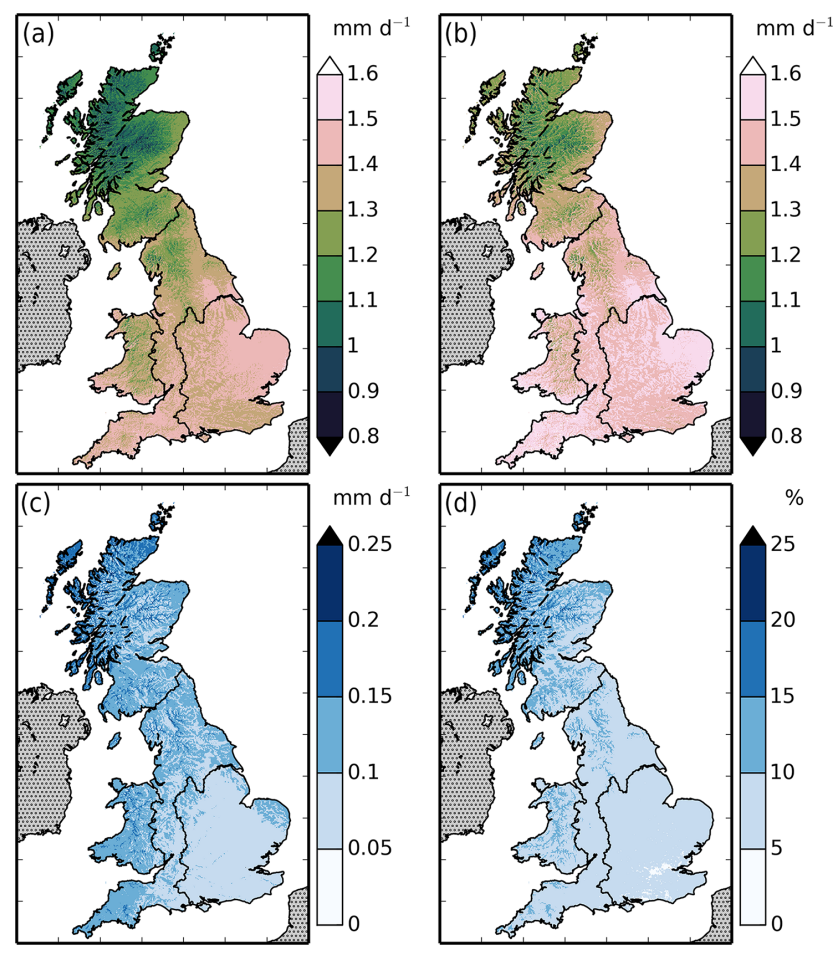

Figure 6. Mean (a) PET, (b) PETI, (c) absolute difference between PETI and PET and (d) relative difference calculated over the years 1961-2012.

\subsection{Spatial and seasonal patterns of PET and PETI}

Both PET and PETI have a distinct gradient from low in the northwest to high in the southeast, and they are both inversely proportional to the elevation (Fig. 6), reflecting the spatial patterns of the meteorological variables. The PETI is $8 \%$ higher than the PET overall but this difference is larger in the north and west, where precipitation rates, and therefore interception, are higher (Fig. 6). In Scotland, the higher interception and lower AED mean that this increase is a larger proportion of the total, with the mean PETI being $11 \%$ larger than the PET (in some areas the difference is more than $25 \%)$. In the English lowlands the difference is smaller, at $6 \%$, but this is a more water-limited region where hydrological modelling can be sensitive to even relatively small adjustments to PET (Kay et al., 2013).

The seasonal climatology of both PET and PETI follow the meteorology (Fig. 7), with high values in the summer and low in the winter. Although the relative difference peaks in winter, the absolute difference between PET and PETI is bimodal, with a peak in March and a smaller peak in October (September in Scotland) (Fig. 7), because in winter the overall AED is low, while in summer the amount of precipitation is low, so the interception correction is small. The seasonal cycle of PET is driven predominantly by the radiative component, which has a much stronger seasonality than the aerodynamic component (Fig. 8). 

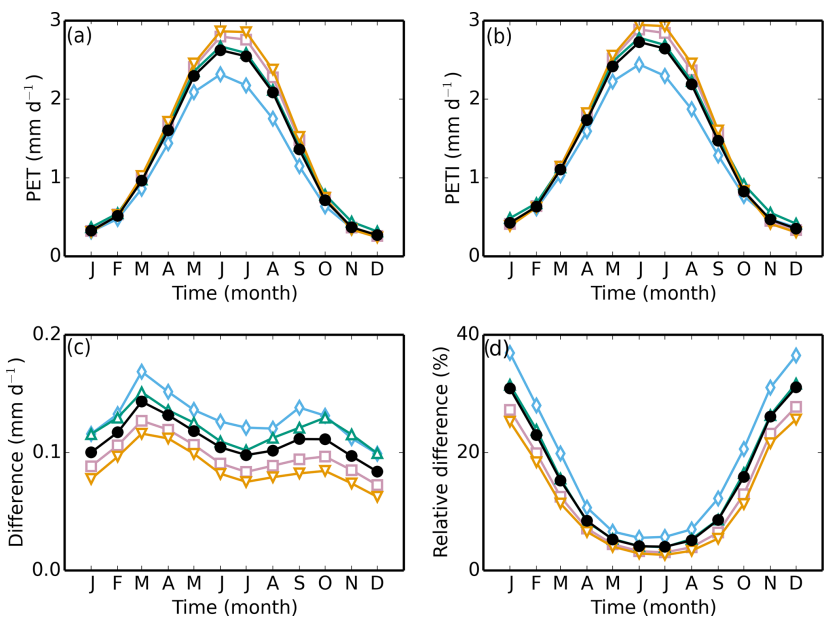

Figure 7. Mean monthly climatology of (a) PET, (b) PETI, (c) absolute difference between PETI and PET, and (d) relative difference, for five different regions of Great Britain, calculated over the years 1961-2012. Symbols as in Fig. 3.

On a monthly or annual timescale, the ratio of PET to precipitation is an indicator of the wetness or dryness of a region (Oldekop, 1911; Andréassian et al., 2016). Low values of PET relative to precipitation indicate wet regions, where evaporation is demand limited, while high values indicate dry, water-limited regions. In the wetter regions (Scotland, Wales) mean monthly PET and PETI (Fig. 7) are on average lower than the mean monthly precipitation (Fig. 3) throughout the year, while in drier regions (England, English lowlands) the mean PET and PETI are higher than the precipitation for much of the summer, highlighting the regions' susceptibility to hydrological drought (Folland et al., 2015).

\section{Decadal trends}

\subsection{Meteorological variables}

Annual means of the meteorological variables (Fig. 9) and the PET and PETI (Fig. 10) were calculated for each region. The trends in these annual means were calculated using linear regression; the significance ( $P$ value $)$ and $95 \%$ confidence intervals (CI) of the slope are calculated specifically allowing for the non-zero lag-1 autocorrelation, to account for possible correlations between adjacent data points (Zwiers and von Storch, 1995; von Storch and Zwiers, 1999). The annual trends can be seen in Table 2. In addition, seasonal means were calculated, with the four seasons defined to be Winter (December-February), Spring (March-May), Summer (June-August) and Autumn (September-November), and trends in these means were also found.

The trends in the annual and seasonal means for all regions are plotted in Fig. 11; trends that are statistically significant at the $5 \%$ level are plotted with solid error bars, while those that
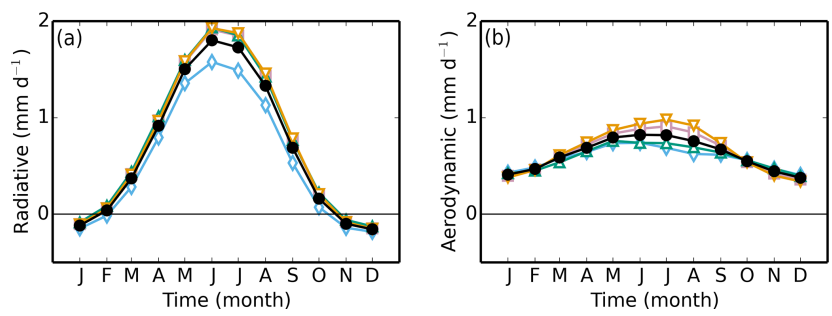

Figure 8. Mean monthly climatology of the (a) radiative and (b) aerodynamic components of the PET for five different regions of Great Britain, calculated over the years 1961-2012. Symbols as in Fig. 3.

are not significant are plotted with dashed lines. The analysis was repeated for each pixel in the $1 \mathrm{~km}$ resolution dataset; maps of these rates of change can be seen in Fig. B1.

There was a statistically significant trend in air temperature in the English Lowlands throughout the year. In the other regions the trends were statistically significant in spring and autumn, and for the annual means. The trends agree with recent trends in the Hadley Centre Central England Temperature (HadCET) dataset (Parker and Horton, 2005) and in temperature records for Scotland (Jenkins et al., 2008) as well as in the CRUTEM4 dataset (Jones et al., 2012). An increase in winter precipitation in Scotland is seen in the current dataset, which leads to a statistically significant increase in the annual mean precipitation of GB. However, all other regions and seasons have no statistically significant trends in precipitation. Long-term observations show that there has been little trend in annual precipitation, but a change in seasonality with wetting winters and drying summers since records began, although with little change over the past 50 years (Jenkins et al., 2008). The statistically significant decline in wind speed in all regions is consistent with the results of McVicar et al. (2012) and Vautard et al. (2010), who report decreasing wind speeds in the Northern Hemisphere over the late 20th century.

\subsection{Potential evapotranspiration}

The trends of the meteorological variables are interesting in their own right. But for hydrology, it is the impact that the trends have on evaporation that matters and that depends on their combination, which can be expressed through PET.

The regional trends of annual mean PET and PETI and the radiative and aerodynamic components of PET can be seen in Table 2, and the trends in the annual and seasonal means are plotted in Fig. 12 for all regions. Maps of the trends can be seen in Fig. B2. The trend in the radiative component of PET is positive over the whole of GB. However, the trend in the aerodynamic component varies; for much of Wales, Scotland and northern England, it is not significant, or is slightly negative, while in Southeast England and Northwest Scotland it is positive. This leads to a positive trend in 

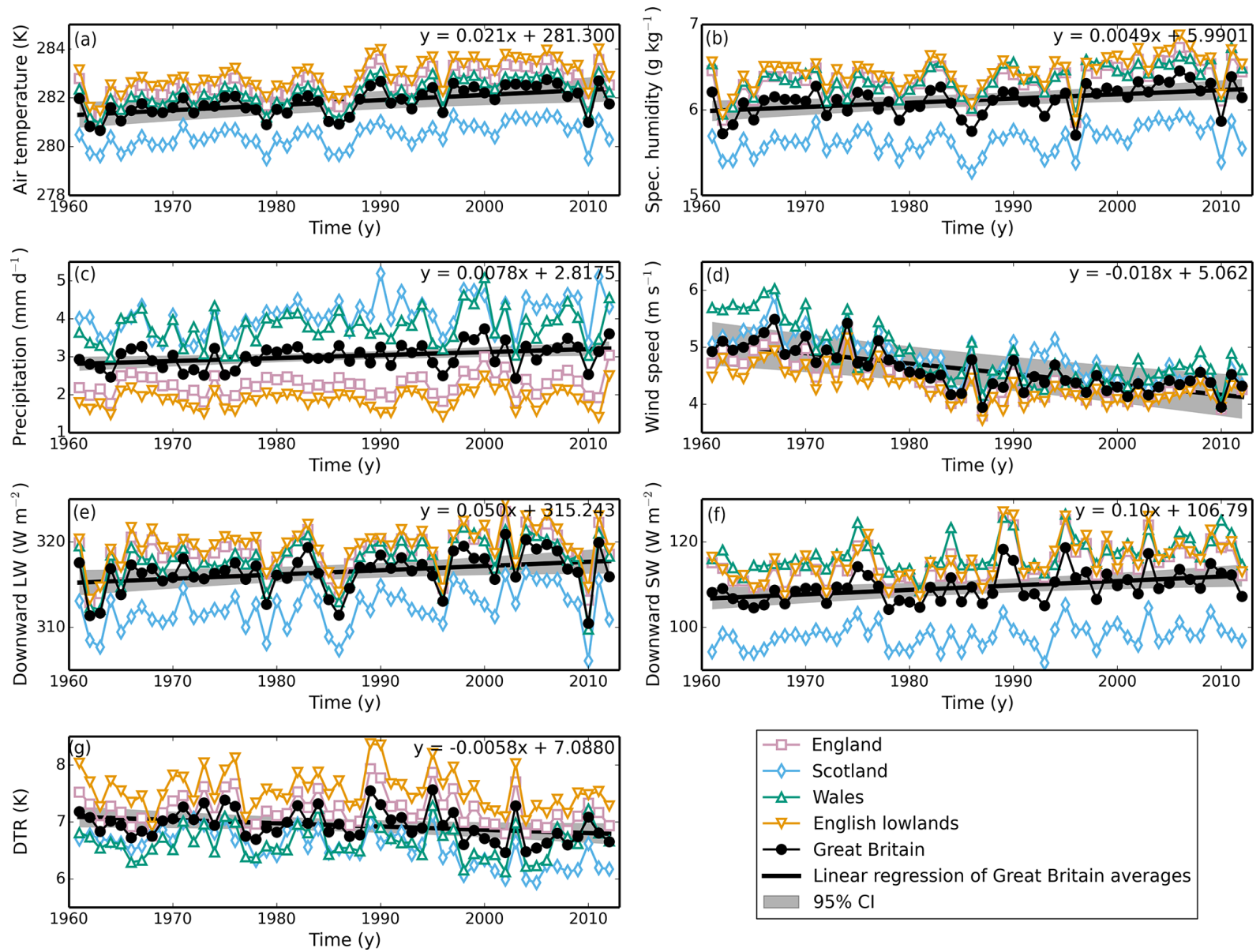

Figure 9. Annual means of the meteorological variables, (a) $1.2 \mathrm{~m}$ air temperature, (b) $1.2 \mathrm{~m}$ specific humidity, (c) precipitation, (d) $10 \mathrm{~m}$ wind speed, (e) downward LW radiation, (f) downward SW radiation, (g) daily air temperature range, over five regions of Great Britain. The solid black lines show the linear regression fit to the Great Britain annual means, while the grey strip shows the $95 \%$ CI of the same fit, assuming a non-zero lag-1 correlation coefficient. The equation of this fit is shown in the top right-hand corner of each plot.
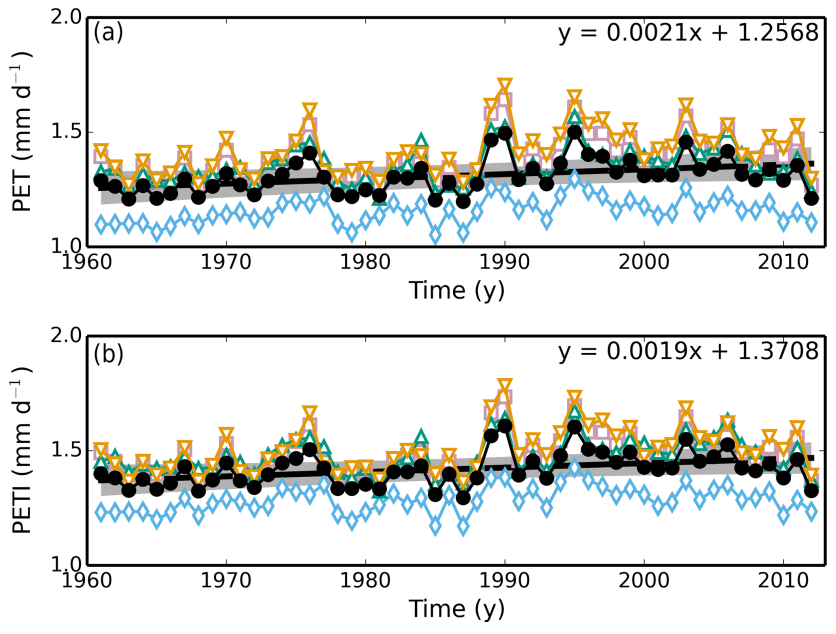

Figure 10. Annual means of (a) PET and (b) PETI for five regions of Great Britain. Symbols as in Fig. 9.
PET over much of GB, but no significant trend in southern Scotland and northern England. There is a statistically significant increase in annual PET in all regions except Wales; the GB trend $\left(0.021 \pm 0.021 \mathrm{~mm} \mathrm{day}^{-1}\right.$ decade $\left.^{-1}\right)$ is equivalent to an increase of $0.11 \pm 0.11 \mathrm{~mm} \mathrm{day}^{-1}$ $(8.3 \pm 8.1 \%$ of the long-term mean) over the whole dataset. Increases in PETI are only statistically significant in England $\left(0.023 \pm 0.023 \mathrm{~mm} \mathrm{day}^{-1}\right.$ decade $\left.^{-1}\right)$ and English lowlands $\left(0.028 \pm 0.025 \mathrm{~mm} \mathrm{day}^{-1}\right.$ decade $\left.^{-1}\right)$, where the increases over the whole dataset are $0.12 \pm 0.12 \mathrm{~mm} \mathrm{day}^{-1} \quad(8.0 \pm 8.0 \%$ of the long-term mean) and $0.15 \pm 0.13 \mathrm{~mm} \mathrm{day}^{-1}(9.7 \pm 8.8 \%$ of the long term mean) respectively. There is a difference in trend between different seasons. In winter, summer and autumn there are no statistically significant trends in PET or PETI, other than the English lowlands in autumn, but the spring is markedly different, with very significant trends $(P<0.0005)$ in all regions. The GB spring trends in PET $\left(0.043 \pm 0.019 \mathrm{~mm} \mathrm{day}^{-1} \mathrm{decade}^{-1}\right)$ and PETI 

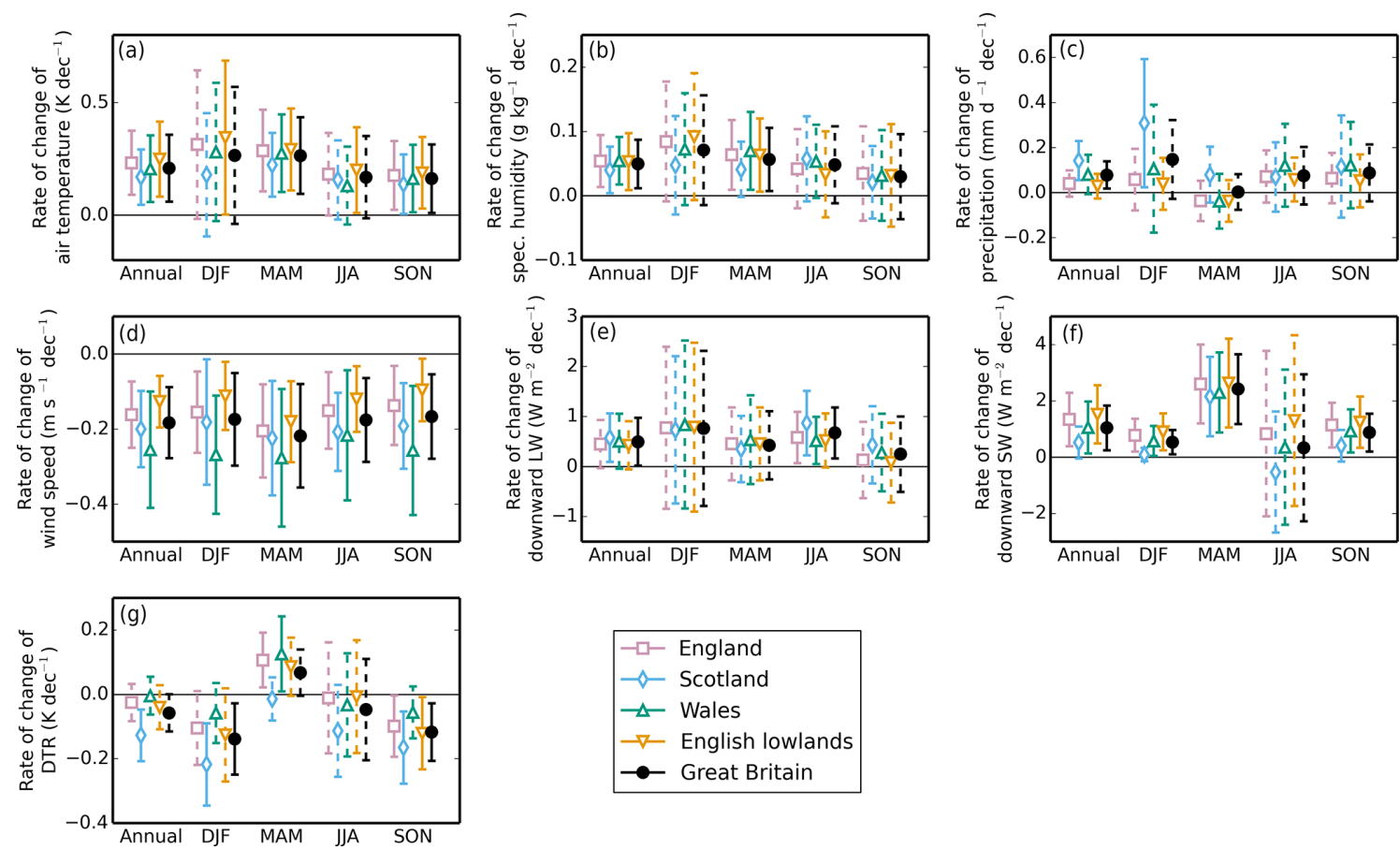

Figure 11. Rate of change of annual and seasonal means of meteorological variables, (a) $1.2 \mathrm{~m}$ air temperature, (b) $1.2 \mathrm{~m}$ specific humidity, (c) precipitation, (d) $10 \mathrm{~m}$ wind speed, (e) downward LW radiation, (f) downward SW radiation, and (g) daily air temperature range, for five regions of Great Britain for the years 1961-2012. Error bars are the $95 \%$ CI calculated assuming a non-zero lag-1 correlation coefficient. Solid error bars indicate slopes that are statistically significant at the $5 \%$ level, dashed error bars indicate slopes that are not significant at the $5 \%$ level.
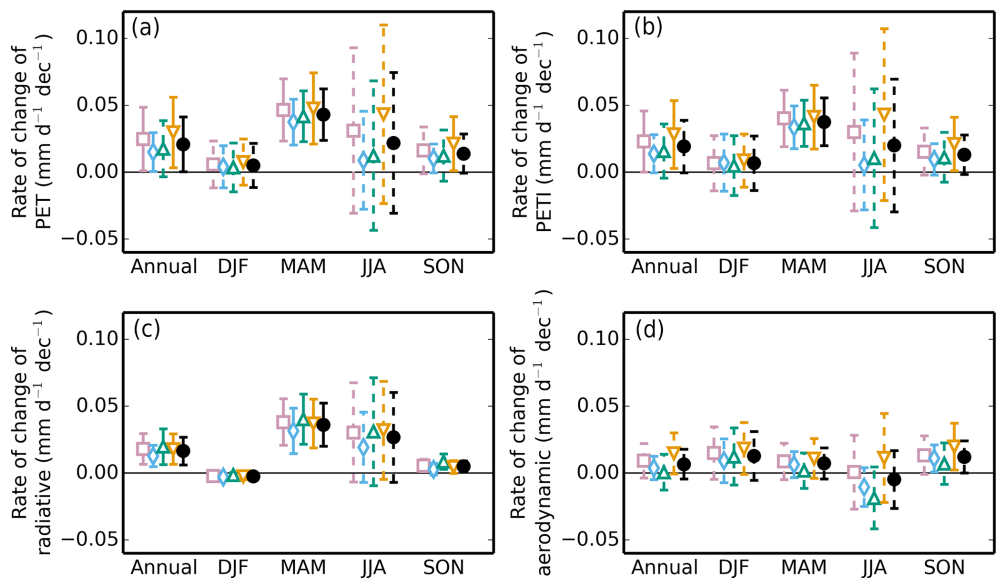

Figure 12. Rate of change of annual and seasonal means of (a) PET, (b) PETI, (c) the radiative component of PET and (d) the aerodynamic component of PET for five regions of Great Britain for the years 1961-2012. Symbols as in Fig. 11.

$\left(0.038 \pm 0.018 \mathrm{~mm} \mathrm{day}^{-1}\right.$ decade $\left.^{-1}\right)$ are equivalent to an increase of $0.22 \pm 0.10 \mathrm{~mm} \mathrm{day}^{-1}(13.8 \pm 6.2 \%$ of the longterm spring mean) and $0.20 \pm 0.09 \mathrm{~mm} \mathrm{day}^{-1}(11.2 \pm 5.3 \%$ of the long-term spring mean) over the length of the dataset respectively. The radiative component of PET has similarly significant trends in spring, while the aerodynamic component has no significant trends in any season, except the English Lowlands in autumn (Fig. 12).
There are few studies of long-term trends in AED in the UK. MORECS provides an estimate of Penman-Monteith PET with interception correction calculated directly from the $40 \mathrm{~km}$ resolution meteorological data (Hough and Jones, 1997; Thompson et al., 1981), and increases can be seen over the dataset (Rodda and Marsh, 2011). But as the PET and PETI in the current dataset are ultimately calculated using the same meteorological data (albeit by different meth- 
Table 2. Rate of change of annual means of meteorological and potential evapotranspiration variables in Great Britain. Bold indicates trends that are significant at the $5 \%$ level. The ranges are given by the $95 \% \mathrm{CI}$.

\begin{tabular}{|c|c|c|c|c|c|}
\hline \multirow[t]{2}{*}{ Variable } & \multicolumn{5}{|c|}{ Rate of change $\pm 95 \%$ CI } \\
\hline & $\begin{array}{r}\text { Great } \\
\text { Britain }\end{array}$ & England & Scotland & Wales & $\begin{array}{l}\text { English } \\
\text { lowlands }\end{array}$ \\
\hline $\begin{array}{l}\text { Air temperature } \\
\left(\mathrm{K} \text { decade }^{-1}\right)\end{array}$ & $0.21 \pm \mathbf{0 . 1 5}$ & $0.23 \pm 0.14$ & $0.17 \pm 0.12$ & $0.21 \pm 0.15$ & $\mathbf{0 . 2 5} \pm \mathbf{0 . 1 7}$ \\
\hline $\begin{array}{l}\text { Specific humidity } \\
\left(\mathrm{g} \mathrm{kg}^{-1} \text { decade }^{-1}\right)\end{array}$ & $\mathbf{0 . 0 4 9} \pm \mathbf{0 . 0 3 7}$ & $\mathbf{0 . 0 5 4} \pm \mathbf{0 . 0 4}$ & $0.040 \pm 0.036$ & $\mathbf{0 . 0 5 5} \pm \mathbf{0 . 0 3 7}$ & $0.053 \pm 0.044$ \\
\hline $\begin{array}{l}\text { Downward SW } \\
\text { radiation } \\
\left(\mathrm{W} \mathrm{m}^{-2} \text { decade }^{-1}\right)\end{array}$ & $1.0 \pm 0.8$ & $1.3 \pm 1.0$ & $0.5 \pm 0.6$ & $1.1 \pm 0.9$ & $1.5 \pm 1.0$ \\
\hline $\begin{array}{l}\text { Downward LW } \\
\text { radiation } \\
\left(\mathrm{W} \mathrm{m}^{-2} \text { decade }^{-1}\right)\end{array}$ & $\mathbf{0 . 5 0} \pm \mathbf{0 . 4 8}$ & $0.45 \pm 0.48$ & $\mathbf{0 . 5 8} \pm \mathbf{0 . 4 8}$ & $0.50 \pm 0.55$ & $0.42 \pm 0.48$ \\
\hline $\begin{array}{l}\text { Wind speed } \\
\left(\mathrm{m} \mathrm{s}^{-1} \text { decade }^{-1}\right)\end{array}$ & $-0.18 \pm 0.09$ & $-0.16 \pm 0.09$ & $-\mathbf{0 . 2 0} \pm \mathbf{0 . 1 0}$ & $-0.25 \pm 0.16$ & $-\mathbf{0 . 1 3} \pm 0.07$ \\
\hline $\begin{array}{l}\text { Precipitation } \\
\left(\mathrm{mm} \mathrm{day}^{-1} \mathrm{decade}^{-1}\right)\end{array}$ & $\mathbf{0 . 0 8} \pm \mathbf{0 . 0 6}$ & $0.04 \pm 0.06$ & $0.14 \pm 0.09$ & $0.08 \pm 0.09$ & $0.03 \pm 0.05$ \\
\hline $\begin{array}{l}\text { Daily temperature } \\
\text { range } \\
\left(\mathrm{Kdecade}^{-1}\right)\end{array}$ & $-0.06 \pm 0.06$ & $-0.03 \pm 0.06$ & $-0.13 \pm 0.08$ & $0.00 \pm 0.06$ & $-0.04 \pm 0.07$ \\
\hline $\begin{array}{l}\text { Relative humidity } \\
\left(\% \text { decade }^{-1}\right)\end{array}$ & $-0.39 \pm 0.44$ & $-0.43 \pm 0.46$ & $-0.33 \pm 0.33$ & $-0.36 \pm 0.4$ & $-0.50 \pm 0.53$ \\
\hline $\begin{array}{l}\text { PET } \\
\left(\mathrm{mm} \mathrm{day}^{-1} \mathrm{decade}^{-1}\right)\end{array}$ & $0.021 \pm 0.021$ & $\mathbf{0 . 0 2 5} \pm \mathbf{0 . 0 2 4}$ & $\mathbf{0 . 0 1 5} \pm \mathbf{0 . 0 1 5}$ & $0.017 \pm 0.021$ & $\mathbf{0 . 0 3} \pm \mathbf{0 . 0 2 6}$ \\
\hline $\begin{array}{l}\text { Radiative } \\
\text { component of } \\
\text { PET } \\
\left(\mathrm{mm} \mathrm{day}^{-1} \text { decade }^{-1}\right)\end{array}$ & $0.016 \pm 0.010$ & $0.018 \pm 0.011$ & $\mathbf{0 . 0 1 3} \pm \mathbf{0 . 0 0 8}$ & $\mathbf{0 . 0 2 0} \pm \mathbf{0 . 0 1 3}$ & $0.018 \pm 0.011$ \\
\hline $\begin{array}{l}\text { Aerodynamic } \\
\text { component of } \\
\text { PET } \\
\left(\mathrm{mm} \mathrm{day}^{-1} \text { decade }^{-1}\right)\end{array}$ & $0.007 \pm 0.011$ & $0.009 \pm 0.013$ & $0.004 \pm 0.009$ & $0.001 \pm 0.013$ & $0.015 \pm 0.015$ \\
\hline $\begin{array}{l}\text { PETI } \\
\left(\mathrm{mm} \mathrm{day}^{-1} \text { decade }^{-1}\right)\end{array}$ & $0.019 \pm 0.020$ & $\mathbf{0 . 0 2 3} \pm \mathbf{0 . 0 2 3}$ & $0.014 \pm 0.014$ & $0.016 \pm 0.020$ & $\mathbf{0 . 0 2 8} \pm \mathbf{0 . 0 2 5}$ \\
\hline
\end{tabular}

ods), it is not unexpected that similar trends should be seen. Site-based studies suggest an increase over recent decades (Burt and Shahgedanova, 1998; Crane and Hudson, 1997), but it is difficult to separate climate-driven trends from local land use trends. A global review paper (McVicar et al., 2012) identified a trend of decreasing AED in the northern hemisphere, driven by decreasing wind speeds, however they also reported significant local variations on trends in pan evaporation, including the increasing trend observed by Stanhill and Möller (2008) at a site in England after 1968. Matsoukas et al. (2011) identified a statistically significant increase in
PET in several regions of the globe, including southern England, between 1983 and 2008, attributing it predominantly to an increase in the radiative component of PET, due to global brightening. However, these results were obtained using reanalysis data, which are limited in ability to capture trends in wind speed. This limitation has been documented in both northern (Pryor et al., 2009) and southern (McVicar et al., 2008) hemispheres.

Regional changes in actual evaporative losses can be estimated indirectly using regional precipitation and runoff or river flow. Using a combination of observations and mod- 
elling, Marsh and Dixon (2012) identified an increase in evaporative losses in Great Britain from 1961 to 2011. Hannaford and Buys (2012) note seasonal and regional differences in trends in observed river flow, suggesting that decreasing spring flows in the English lowlands are indicative of increasing AED. However, changing evaporative losses can also be due to changing supply through precipitation, so it is important to formally attribute the trends in PET to changing climate, in order to understand changing evapotranspiration.

\subsection{Attribution of trends in potential evapotranspiration}

In order to attribute changes in PET to changes in climate, the rate of change of PET, $\mathrm{d} E_{\mathrm{p}} / \mathrm{d} t\left(\mathrm{~mm}\right.$ day $\left.^{-1} \mathrm{decade}^{-1}\right)$, can be calculated as a function of the rate of change of each input variable (Roderick et al., 2007),

$$
\begin{aligned}
\frac{\mathrm{d} E_{\mathrm{P}}}{\mathrm{d} t} & =\frac{\mathrm{d} E_{\mathrm{P}}}{\mathrm{d} T_{\mathrm{a}}} \frac{\mathrm{d} T_{\mathrm{a}}}{\mathrm{d} t}+\frac{\mathrm{d} E_{\mathrm{P}}}{\mathrm{d} q_{\mathrm{a}}} \frac{\mathrm{d} q_{\mathrm{a}}}{\mathrm{d} t}+\frac{\mathrm{d} E_{\mathrm{P}}}{\mathrm{d} u_{10}} \frac{\mathrm{d} u_{10}}{\mathrm{~d} t}+\frac{\mathrm{d} E_{\mathrm{P}}}{\mathrm{d} L_{\mathrm{d}}} \frac{\mathrm{d} L_{\mathrm{d}}}{\mathrm{d} t} \\
& +\frac{\mathrm{d} E_{\mathrm{P}}}{\mathrm{d} S_{\mathrm{d}}} \frac{\mathrm{d} S_{\mathrm{d}}}{\mathrm{d} t} .
\end{aligned}
$$

Note that we exclude the surface air pressure, because this dataset uses a mean monthly climatology as the interannual variability of air pressure is negligible. The derivative of the PET with respect to each of the meteorological variables can be found analytically (Appendix C). The derivatives are calculated from the daily meteorological data at $1 \mathrm{~km}$ resolution. Substituting the slopes of the linear regressions of the gridded annual means (Appendix B) for the rate of change of each variable with time, and the overall time average of the derivatives of PET with respect to the meteorological variables, the contribution of each variable to the rate of change of PET is calculated at $1 \mathrm{~km}$ resolution. These are then averaged over the regions of interest. The same is also applied to the radiative and aerodynamic components independently.

Note that this can also be applied to the regional means of the derivatives of PET and the regional trends in the meteorological variables. The results are compared in Table 3 and the two approaches are consistent. For the regional analysis, we also quote the $95 \%$ CI. However, for the gridded values, there is such high spatial coherence that combining the $95 \%$ CI over the region results in unreasonably constrained results. We therefore use the more conservative CI obtained from the regional analysis. Also note that this method assumes that the rate of change of the variables with respect to time is constant over the seasonal cycle (and thus the product of the means is equal to the mean of the products), and indeed this is how it is often applied (Donohue et al., 2010; Lu et al., 2016). The effect of this assumption was investigated by repeating the analysis with seasonal trends and means, but this makes negligible difference to the results.

Figure 13 shows the contribution of each meteorological variable to the rate of change of the annual mean PET and to the radiative and aerodynamic components and compares the total attributed trend to that obtained by linear regression. The percentage contribution is in Table 4, calculated as a fraction of the fitted trend. The final column shows the total attributed trend (i.e. the sum of the previous columns) as a percentage of the fitted trend, to demonstrate the success of the attribution at recovering the fitted trends. For the PET trend and for the trend in the radiative component, these values generally sum to the linear regression to within a few percent. However, for the aerodynamic component, the fitted trends are much smaller than the statistical uncertainty. This means that there can be a large and/or negative percentage difference between the attributed and fitted trends, even when the absolute difference is negligible.

The largest overall contribution to the rate of change of PET comes from increasing air temperature, which has the effect of increasing the aerodynamic component but decreasing the radiative component. The latter effect is due to approximating the surface temperature with the air temperature in the calculation of upwelling LW radiation. This assumption is applied as it simplifies the surface energy balance but it may introduce artefacts into the calculation of PET. A more thorough formulation of PET, which linearises the net radiation in the derivation of the Penman-Monteith equation, can be calculated to allow for a non-negligible difference between air and surface temperature (Monteith, 1981; Thompson et al., 1981), but the difference between the more thorough formulation and the formulation used here is small, particularly for the temperature range of GB.

Note that in this calculation we are assuming that air temperature and downward LW radiation vary independently, while in reality (and implicit in the calculation of downward LW in Sect. 2.4), downward LW radiation is also a function of the air temperature so that increases in downward LW may broadly cancel the increasing upwelling LW radiation. If we instead were to use net LW radiation as the independent variable, it is likely that dependence of the rate of change of the radiative component on air temperature would be reduced in magnitude and compensated by the rate of change of net LW radiation.

Overall the next largest increases are caused by increasing downward SW radiation, particularly in the English regions in the spring, as it increases the radiative component of PET. However, in Scotland and Wales, the increasing downward LW radiation is also important. Increasing specific humidity strongly decreases the PET by decreasing the aerodynamic component, while the decreasing wind speed has the effect of increasing the radiative component, but more strongly decreasing the aerodynamic component, so overall it tends to cause a decrease in PET. Since the increasing air temperature and downward LW and SW radiation have the effect of increasing PET, but the increasing specific humidity and decreasing wind speed tend to decrease it, then the overall trend is positive, but smaller than the trend due to air temperature alone. 


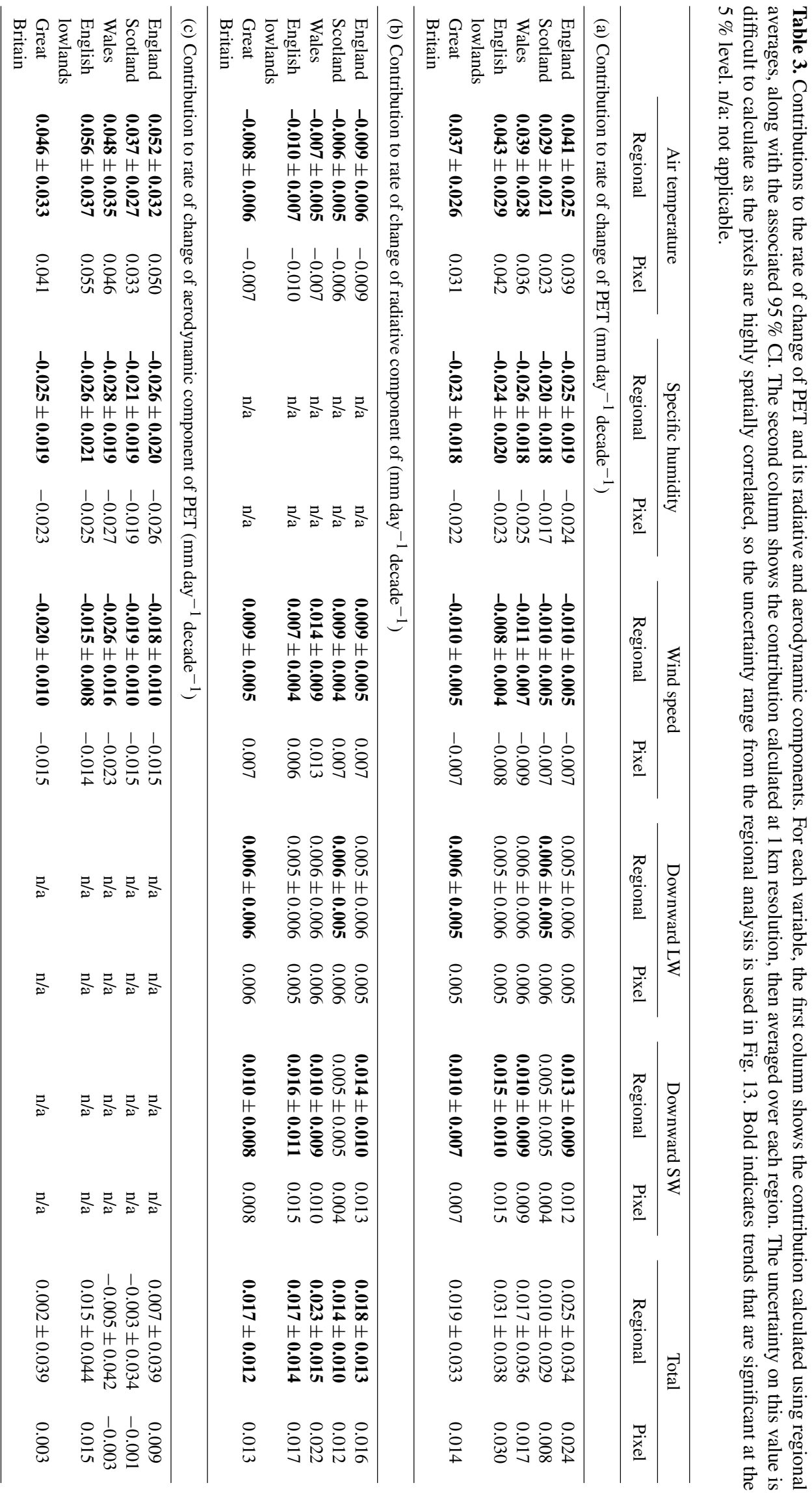



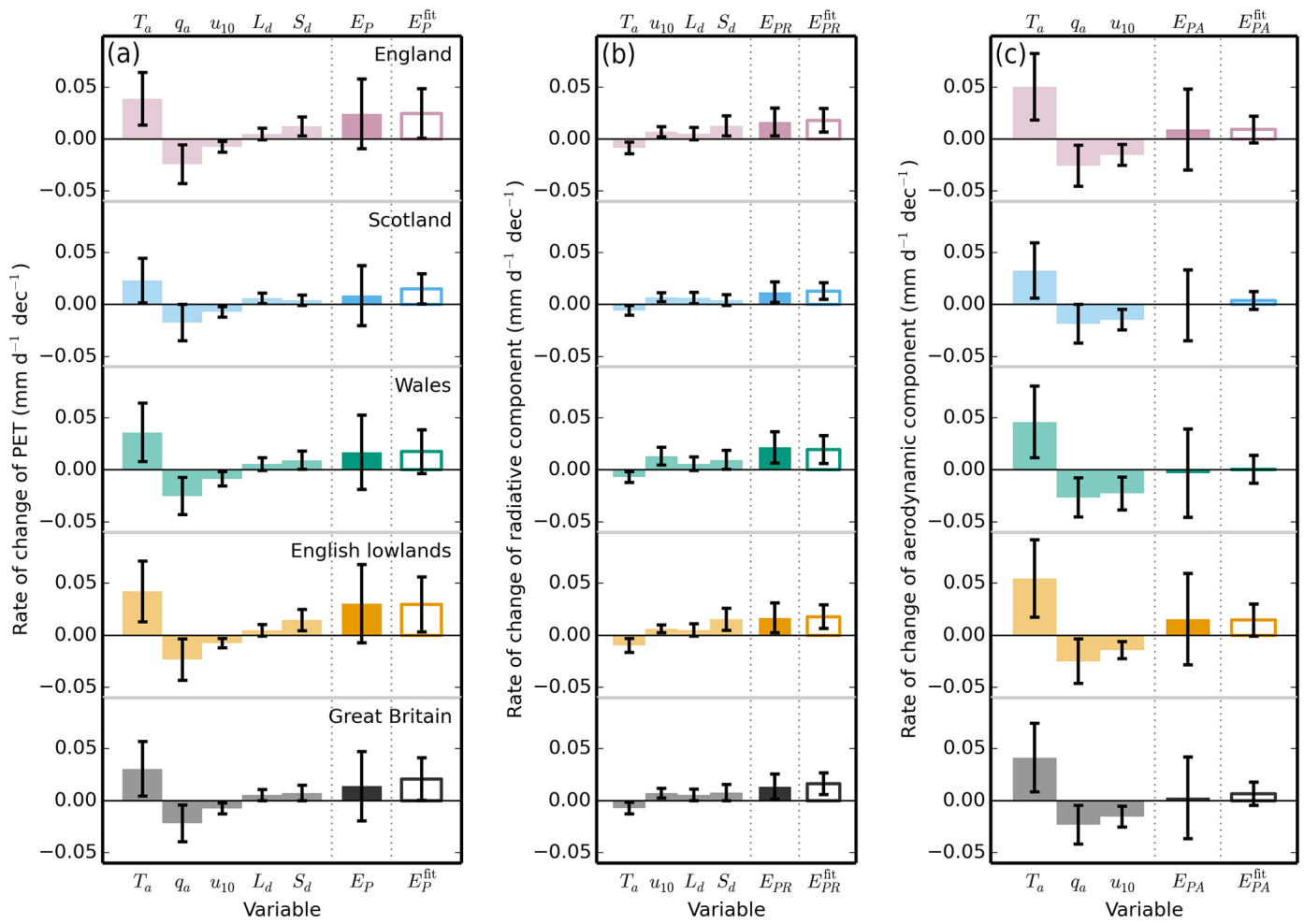

Figure 13. The contribution of the rate of change of each meteorological variable to the rate of change of (a) PET, (b) the radiative component and (c) the aerodynamic component. The first five (four; three) bars are the contribution to the rate of change of annual mean PET from the rate of change of each of the variables, calculated per pixel, then averaged over each region. Each bar has an error bar showing the $95 \% \mathrm{CI}$ on each value. Since the pixels are highly spatially correlated, we use the more conservative CI calculated by applying this analysis to the regional means. The next bar is the sum of the other bars and shows the attributed rate of change of annual mean PET. The final bar shows the slope and its associated CI obtained from the linear regression of the mean annual PET for each region.

\subsection{Relative humidity}

The increase in PET due to increasing air temperature is largely cancelled by the decrease due to increasing specific humidity so that the overall trend is smaller than the contribution to the increase from air temperature alone. However, although we have assumed that specific humidity and air temperature are independent variables, they are in fact coevolving in a warming atmosphere. As air temperature increases, the saturated specific humidity increases according to the Clausius-Clapeyron relation (Schneider et al., 2010). However, since evaporation also increases with rising temperature, the increased water flux into the atmosphere ensures that specific humidity also increases and it can be shown that there is likely to be little change in global relative humidity even with significant change in global temperature (Held and Soden, 2006; Schneider et al., 2010), although this may vary regionally over land (Dai, 2006). Although it is not completely independent of air temperature, an alternative way of assessing the drivers of AED is to consider relative humidity, $\mathrm{RH}$, as the independent humidity variable. In this case, the PET can be recast in terms of relative humidity, such that
$E_{\mathrm{P}}=\frac{t_{\mathrm{d}}}{\lambda} \frac{\Delta A+\frac{c_{\mathrm{p}} \rho_{\mathrm{a}}}{r_{\mathrm{a}}} q_{\mathrm{s}}(1-\mathrm{RH})}{\Delta+\gamma\left(1+\frac{r_{\mathrm{s}}}{r_{\mathrm{a}}}\right)}$.

Relative humidity is calculated from the specific humidity using

$\mathrm{RH}=\frac{q_{\mathrm{a}}}{q_{\mathrm{s}}}$.

Although in this case relative humidity is a function of air temperature, through the saturated specific humidity, in reality they are often found to behave as independent variables. It has been shown that there is little cancellation of the air temperature and relative humidity terms when studying both historical data and future climate projections (Scheff and Frierson, 2014).

The relative humidity annual means, mean monthly climatology and seasonal trends can be seen in Fig. 14. We find a statistically significant negative trend in relative humidity in the spring and autumn (except Wales in the autumn) but no overall negative trend in winter or summer and no significant trend in the annual means. Maps of the overall mean relative 
Table 4. Contribution of the trend in each variable to the trends in annual mean PET and its radiative and aerodynamic components as a percentage of the fitted trend in PET and its components. n/a: not applicable.

\begin{tabular}{|c|c|c|c|c|c|c|}
\hline & $\begin{array}{r}\text { Air } \\
\text { temperature }\end{array}$ & $\begin{array}{l}\text { Specific } \\
\text { humidity }\end{array}$ & $\begin{array}{l}\text { Wind } \\
\text { speed }\end{array}$ & $\begin{array}{r}\text { Downward } \\
\text { LW }\end{array}$ & $\begin{array}{r}\text { Downward } \\
\text { SW }\end{array}$ & Total \\
\hline \multicolumn{7}{|c|}{ (a) Potential evapotranspiration (PET) } \\
\hline England & $154 \%$ & $-88 \%$ & $-22 \%$ & $17 \%$ & $47 \%$ & $108 \%$ \\
\hline Scotland & $150 \%$ & $-74 \%$ & $-23 \%$ & $26 \%$ & $18 \%$ & $97 \%$ \\
\hline Wales & $200 \%$ & $-130 \%$ & $-38 \%$ & $28 \%$ & $50 \%$ & $109 \%$ \\
\hline English & $142 \%$ & $-77 \%$ & $-20 \%$ & $15 \%$ & $45 \%$ & $105 \%$ \\
\hline \multicolumn{7}{|l|}{ lowlands } \\
\hline Great Britain & $155 \%$ & $-87 \%$ & $-23 \%$ & $19 \%$ & $31 \%$ & $96 \%$ \\
\hline \multicolumn{7}{|c|}{ (b) Radiative component of PET } \\
\hline England & $-47 \%$ & $\mathrm{n} / \mathrm{a}$ & $40 \%$ & $28 \%$ & $71 \%$ & $92 \%$ \\
\hline Scotland & $-42 \%$ & $\mathrm{n} / \mathrm{a}$ & $62 \%$ & $46 \%$ & $36 \%$ & $102 \%$ \\
\hline Wales & $-34 \%$ & $\mathrm{n} / \mathrm{a}$ & $69 \%$ & $29 \%$ & $52 \%$ & $116 \%$ \\
\hline English & $-53 \%$ & $\mathrm{n} / \mathrm{a}$ & $35 \%$ & $27 \%$ & $86 \%$ & $95 \%$ \\
\hline \multicolumn{7}{|l|}{ lowlands } \\
\hline Great Britain & $-44 \%$ & $\mathrm{n} / \mathrm{a}$ & $46 \%$ & $31 \%$ & $53 \%$ & $87 \%$ \\
\hline \multicolumn{7}{|c|}{ (c) Aerodynamic component of PET } \\
\hline England & $245 \%$ & $-115 \%$ & $-48 \%$ & $\mathrm{n} / \mathrm{a}$ & $\mathrm{n} / \mathrm{a}$ & $82 \%$ \\
\hline Scotland & $68 \%$ & $-14 \%$ & $-33 \%$ & $\mathrm{n} / \mathrm{a}$ & $\mathrm{n} / \mathrm{a}$ & $21 \%$ \\
\hline Wales & $-135 \%$ & $72 \%$ & $-42 \%$ & $\mathrm{n} / \mathrm{a}$ & $\mathrm{n} / \mathrm{a}$ & $-105 \%$ \\
\hline English & $282 \%$ & $-126 \%$ & $-47 \%$ & $\mathrm{n} / \mathrm{a}$ & $\mathrm{n} / \mathrm{a}$ & $109 \%$ \\
\hline \multicolumn{7}{|l|}{ lowlands } \\
\hline Great Britain & $168 \%$ & $-76 \%$ & $-44 \%$ & $\mathrm{n} / \mathrm{a}$ & $\mathrm{n} / \mathrm{a}$ & $48 \%$ \\
\hline
\end{tabular}

humidity and the trend in the annual mean are in Fig. B3. There are only small regions in the west of Scotland and the east and southwest of England where there are significant trends in the annual mean.

We calculate an alternative attribution using relative humidity as a variable, rather than specific humidity, such that

$$
\begin{aligned}
\frac{\mathrm{d} E_{\mathrm{P}}}{\mathrm{d} t} & =\frac{\mathrm{d} E_{\mathrm{P}}}{\mathrm{d} T_{\mathrm{a}}} \frac{\mathrm{d} T_{\mathrm{a}}}{\mathrm{d} t}+\frac{\mathrm{d} E_{\mathrm{P}}}{\mathrm{dRH}} \frac{\mathrm{dRH}}{\mathrm{d} t}+\frac{\mathrm{d} E_{\mathrm{P}}}{\mathrm{d} u_{10}} \frac{\mathrm{d} u_{10}}{\mathrm{~d} t}+\frac{\mathrm{d} E_{\mathrm{P}}}{\mathrm{d} L_{\mathrm{d}}} \frac{\mathrm{d} L_{\mathrm{d}}}{\mathrm{d} t} \\
& +\frac{\mathrm{d} E_{\mathrm{P}}}{\mathrm{d} S_{\mathrm{d}}} \frac{\mathrm{d} S_{\mathrm{d}}}{\mathrm{d} t} .
\end{aligned}
$$

We then calculate the derivative of the PET with respect to relative humidity and the derivatives with respect to air temperature and pressure are now taken at constant $\mathrm{RH}$ rather than constant $q_{\mathrm{a}}$, so these are also recalculated. See Appendix $\mathrm{C}$ for details.

Table 5 and Fig. 15 show the contribution of the different variables to the rate of change of PET with this alternative formulation. The total attributed change is nearly the same as that in Fig. 13, although there are small differences due to statistical uncertainty in the fits. The percentage contributions as a proportion of the fitted trend can be seen in Table 6. The contributions of downward SW and LW radiation and of wind speed to the rate of change of PET are unchanged. Although it is not statistically significant, the neg-
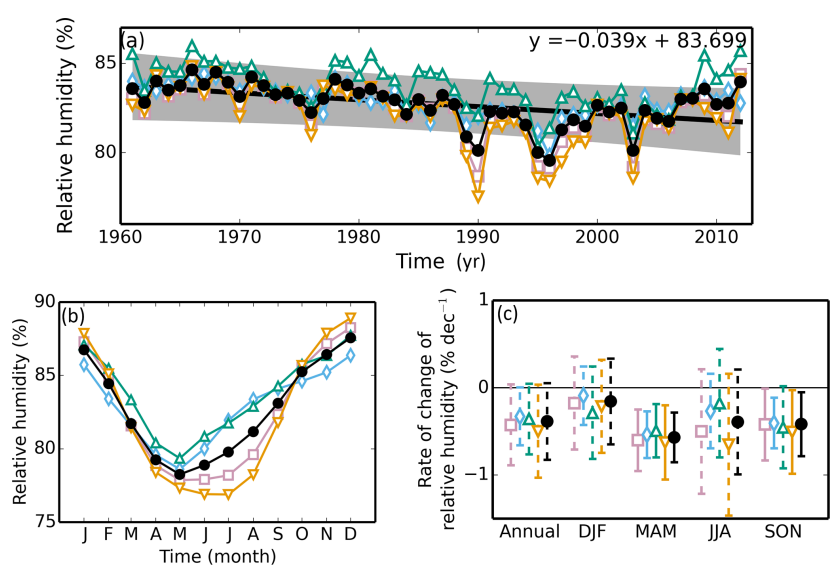

Figure 14. Regional annual means (a), regional mean monthly climatology (b) and regional rates of change of relative humidity for the years 1961-2012.

ative trend in relative humidity leads to an increase in the aerodynamic component, which is larger than the increase due to increasing downward SW radiation. The contribution of air temperature to the rate of change is significantly reduced compared to the specific humidity formulation. The air temperature-driven decrease in the radiative component now 

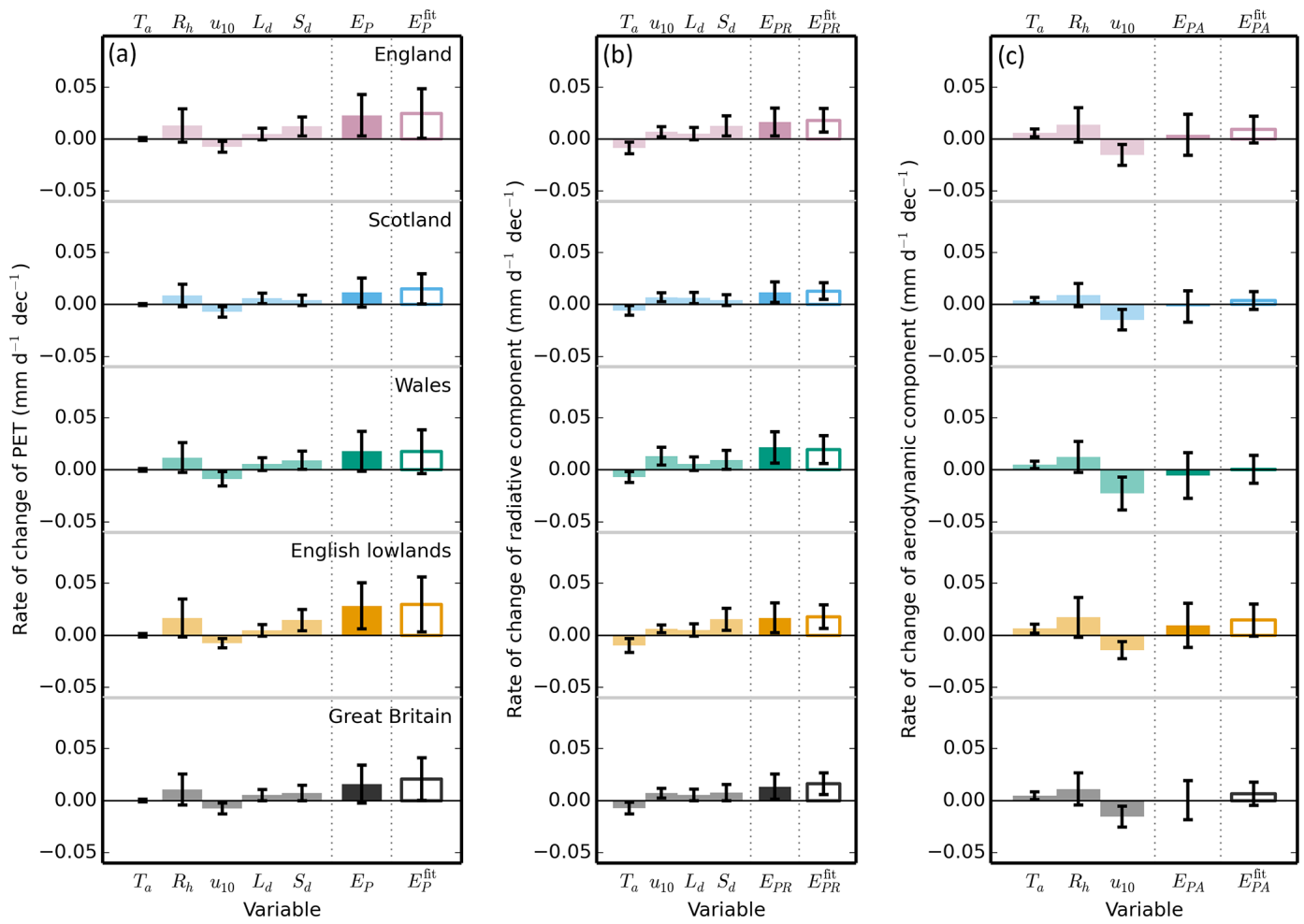

Figure 15. The contribution of the rate of change of each meteorological variable to the rate of change of (a) PET, (b) the radiative component and (c) the aerodynamic component, with relative humidity instead of specific humidity. The first five (four; three) bars are the contribution to the rate of change of annual mean PET from the rate of change of each of the variables, calculated per pixel, then averaged over each region. Each bar has an error bar showing the $95 \%$ CI on each value. Since the pixels are highly spatially correlated, we use the more conservative CI calculated by applying this analysis to the regional means. The next bar is the sum of the other bars and shows the attributed rate of change of annual mean PET. The final bar shows the slope and its associated CI obtained from the linear regression of the mean annual PET for each region.

largely cancels the temperature-driven increase in the aerodynamic component, which is much smaller than in Sect. 4.3 as it now implicitly includes the rising specific humidity. However, the effect of air temperature on the radiative component comes through the effect of air temperature on the upwelling LW radiation in the calculation of net radiation and this is dependent on the simplifying assumption that the surface temperature is equal to the air temperature when solving the energy balance. If the fully linearised version of the Penman-Monteith equation were used (Monteith, 1981), then the dependence on air temperature would be more complicated as it would account for a non-negligible difference between air and surface temperature. This may result in a different contribution of air temperature to the changing PET, although this difference is likely to be small.

\section{Discussion}

These high-resolution datasets provide insight into the effect of the changing climate of Great Britain on AED over the past five decades. There have been significant climatic trends in the UK since 1961; in particular rising air temperature and specific humidity, decreasing wind speed and decreasing cloudiness. Although some are positive and some negative, these meteorological trends combine to give statistically significant trends in PET.

Wind speeds have decreased more significantly in the west than the east, and show a consistent decrease across seasons. Contrary to Donohue et al. (2010) and McVicar et al. (2012), this study finds that the change in wind speed of the late 20th and early 21 st centuries has not had a dominant influence on PET over the period of study, although it has mitigated the increasing trend in PET. However, the previous studies were concerned with open-water Penman evaporation, which has a simpler (proportional) dependence on wind speed than the Penman-Monteith PET considered here (Schymanski and Or, 2015).

The air temperature trend in this study of $0.21 \pm 0.15 \mathrm{~K} \mathrm{decade}^{-1}$ in GB is consistent with observed global and regional trends (Hartmann et al., 2013; Jenkins et al., 2008). The temperature trend is responsible for a large contribution to the trend in PET, although the large negative contribution from the specific humidity (as 


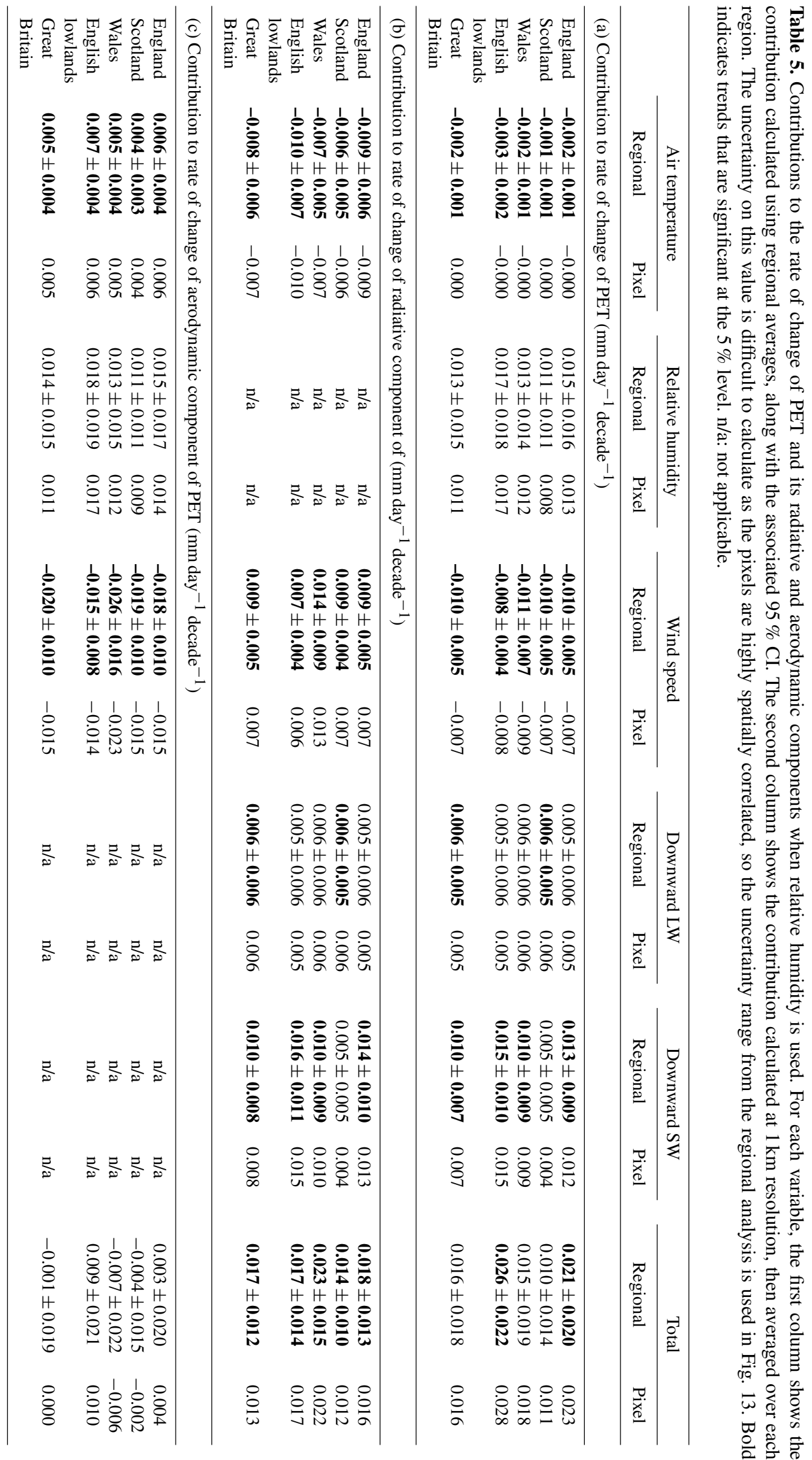


Table 6. Contribution of the trend in each variable to the trends in annual mean PET and its radiative and aerodynamic components as a percentage of the fitted trend in PET and its components when relative humidity is used. n/a: not applicable.

\begin{tabular}{|c|c|c|c|c|c|c|}
\hline & $\begin{array}{r}\text { Air } \\
\text { temperature }\end{array}$ & $\begin{array}{l}\text { Relative } \\
\text { humidity }\end{array}$ & $\begin{array}{l}\text { Wind } \\
\text { speed }\end{array}$ & $\begin{array}{r}\text { Downward } \\
\text { LW }\end{array}$ & $\begin{array}{r}\text { Downward } \\
\text { SW }\end{array}$ & Total \\
\hline \multicolumn{7}{|c|}{ (a) Potential evapotranspiration (PET) } \\
\hline England & $0 \%$ & $57 \%$ & $-22 \%$ & $17 \%$ & $47 \%$ & $99 \%$ \\
\hline Scotland & $0 \%$ & $65 \%$ & $-23 \%$ & $26 \%$ & $18 \%$ & $85 \%$ \\
\hline Wales & $0 \%$ & $68 \%$ & $-38 \%$ & $27 \%$ & $50 \%$ & $107 \%$ \\
\hline English & $0 \%$ & $57 \%$ & $-20 \%$ & $15 \%$ & $45 \%$ & $97 \%$ \\
\hline \multicolumn{7}{|l|}{ lowlands } \\
\hline Great Britain & $0 \%$ & $60 \%$ & $-23 \%$ & $19 \%$ & $31 \%$ & $87 \%$ \\
\hline \multicolumn{7}{|c|}{ (b) Radiative component of PET } \\
\hline England & $-47 \%$ & $\mathrm{n} / \mathrm{a}$ & $40 \%$ & $28 \%$ & $71 \%$ & $92 \%$ \\
\hline Scotland & $-42 \%$ & $\mathrm{n} / \mathrm{a}$ & $62 \%$ & $46 \%$ & $36 \%$ & $102 \%$ \\
\hline Wales & $-34 \%$ & $\mathrm{n} / \mathrm{a}$ & $69 \%$ & $29 \%$ & $52 \%$ & $116 \%$ \\
\hline English & $-53 \%$ & $\mathrm{n} / \mathrm{a}$ & $35 \%$ & $27 \%$ & $86 \%$ & $95 \%$ \\
\hline \multicolumn{7}{|l|}{ lowlands } \\
\hline Great Britain & $-44 \%$ & $\mathrm{n} / \mathrm{a}$ & $46 \%$ & $31 \%$ & $53 \%$ & $87 \%$ \\
\hline \multicolumn{7}{|c|}{ (c) Aerodynamic component of PET } \\
\hline England & $29 \%$ & $78 \%$ & $-48 \%$ & $\mathrm{n} / \mathrm{a}$ & $\mathrm{n} / \mathrm{a}$ & $59 \%$ \\
\hline Scotland & $8 \%$ & $14 \%$ & $-33 \%$ & $\mathrm{n} / \mathrm{a}$ & $\mathrm{n} / \mathrm{a}$ & $-11 \%$ \\
\hline Wales & $-15 \%$ & $-33 \%$ & $-42 \%$ & $\mathrm{n} / \mathrm{a}$ & $\mathrm{n} / \mathrm{a}$ & $-90 \%$ \\
\hline English & $33 \%$ & $98 \%$ & $-47 \%$ & $\mathrm{n} / \mathrm{a}$ & $\mathrm{n} / \mathrm{a}$ & $84 \%$ \\
\hline \multicolumn{7}{|l|}{ lowlands } \\
\hline Great Britain & $19 \%$ & $52 \%$ & $-44 \%$ & $\mathrm{n} / \mathrm{a}$ & $\mathrm{n} / \mathrm{a}$ & $27 \%$ \\
\hline
\end{tabular}

well as a small negative contribution from wind speed) means that the overall trend is smaller than the temperature trend alone.

When the attribution is recast in terms of relative humidity, the effect of air temperature is much smaller, supporting the hypothesis that the temperature and specific humidity components cancel because their changes are part of the same thermodynamic warming processes. Much of the increase in the aerodynamic component due to air temperature is cancelled by the decrease of the radiative component, which is due to the effect of air temperature on the calculated upwelling LW radiation. However this is because of the assumption that surface temperature can be approximated with air temperature, thus the real physical contribution of air temperature in the relative humidity formulation is likely to be roughly equal to the increase in the aerodynamic component. Although the relative humidity does not have a statistically significant trend overall (although there are significant trends in spring and for some regions in autumn), it is large enough that the negative trend in relative humidity is the largest contribution to the increasing PET, followed by the downward $\mathrm{SW}$ radiation. This corresponds well to recent findings in Spain (Vicente-Serrano et al., 2016).

The trend in relative humidity is consistent with that seen in historical regional (Jenkins et al., 2008) and global (Dai,
2006; Willett et al., 2014) analyses. Although not statistically significant overall, it contributes to between 57 and $68 \%$ of the trends in PET (between 39 and $46 \%$ or the trends in spring PET). Globally trends in relative humidity vary spatially, with mid-latitudes showing a decrease and the tropics and high-latitudes showing an increase, despite an overall increase in specific humidity over land, particularly in the Northern Hemisphere (Dai, 2006; Willett et al., 2014). In these global analyses, Great Britain is in a region of transition between decreasing relative humidity in western Europe and increasing relative humidity in Scandinavia, so that small decreasing trends are found, but they are not significant; this is consistent with our findings. We found the relative humidity to be decreasing significantly in spring, which is also when the downward SW is increasing. This is consistent with reduced precipitation and cloud cover due to changing weather patterns (Sutton and Dong, 2012).

Increasing solar radiation has been shown to increase spring and annual AED, contributing to between 18 and $50 \%$ of the fitted trend in annual PET, and to between 43 and $53 \%$ of the fitted trend in spring PET. Two main mechanisms can be responsible for changing solar radiation: changing cloud cover and changing aerosol concentrations. Changing aerosol emissions have been shown to have had a significant effect on solar radiation in the 20th century. In Eu- 
rope, global dimming due to increased aerosol concentrations peaked around 1980, followed by global brightening as aerosol concentrations decreased (Wild, 2009). Observations of changing continental runoff and river flow in Europe over the 20th century have been attributed to changing aerosol concentrations, via their effect on solar radiation, and thus AED (Gedney et al., 2014).

In this study we use the duration of bright sunshine to calculate the solar radiation, using empirical coefficients which do not vary with year, so aerosol effects are not explicitly included and the trend in downward SW is driven by the increase in sunshine hours in the MORECS dataset $\left(0.088 \pm 0.055 \mathrm{~h} \mathrm{day}^{-1} \mathrm{decade}^{-1}\right.$ over GB$)$. The coefficients used in this study to convert sunshine hours to radiation fluxes were empirically derived in 1978; the derivation used data from the decade 1966-1975, as this period was identified to be before reductions in aerosol emissions had begun to significantly alter observed solar radiation (Cowley, 1978). Despite this, the trend in SW radiation in the current dataset from 1979 onwards $\left(1.4 \pm 1.4 \mathrm{~W} \mathrm{~m}^{-2}\right.$ decade $\left.^{-1}\right)$ is consistent, within uncertainties, with that seen over GB in the WFDEI data $\left(0.9 \pm 1.1 \mathrm{~W} \mathrm{~m}^{-2}\right.$ decade $\left.^{-1}\right)$, which is biascorrected to observations and includes explicit aerosol effects (Weedon et al., 2014).

It has been suggested that aerosol effects also implicitly affect sunshine duration since in polluted areas there will be fewer hours above the official "sunshine hours" threshold of $120 \mathrm{~W} \mathrm{~m}^{-2}$ (Helmes and Jaenicke, 1986). Several regional studies have shown trends in sunshine hours that are consistent with the periods of dimming and brightening across the globe (e.g. Liley, 2009; Sanchez-Lorenzo et al., 2008, 2009; Stanhill and Cohen, 2005), and several have attempted to quantify the relative contribution of trends in cloud cover and aerosol loading (e.g. Sanchez-Lorenzo and Wild, 2012 in Switzerland, see Sanchez-Romero et al., 2014 for a review). Therefore, it may be that some of the brightening trend seen in the current dataset is due to the implicit signal of aerosol trends in the MORECS sunshine duration, although this is likely to be small compared to the effects of changing cloud cover.

The trends in the MORECS sunshine duration used in this study are consistent with changing weather patterns which may be attributed to the Atlantic Multidecadal Oscillation (AMO). The AMO has been shown to cause a decrease in spring precipitation (and therefore cloud cover) in northern Europe over recent decades (Sutton and Dong, 2012), and the trend in MORECS sunshine hours is dominated by an increase in the spring mean. This has also been seen in Europewide sunshine hours data (Sanchez-Lorenzo et al., 2008) and is also consistent with the falling spring relative humidity found in the current study. On the other hand, the effect of changing aerosols on sunshine hours is expected to be largest in the winter (Sanchez-Lorenzo et al., 2008). However, it would not be possible to directly identify either of these ef- fects on the sunshine duration without access to longer data records.

The inclusion of explicit aerosol effects in the coefficients of the Ångström-Prescott equation would be expected to reduce the positive trend in AED in the first two decades of the dataset, and increase it after 1980. Gedney et al. (2014) attribute a decrease in European solar radiation of $10 \mathrm{~W} \mathrm{~m}^{-2}$ between the periods 1901-1910 and 1974-1980, and an increase of $4 \mathrm{~W} \mathrm{~m}^{-2}$ from 1974-1984 to 1990-1999 to changing aerosol contributions. Applying these trends to the current dataset, with a turning point at 1980, would double the overall increase in solar radiation in Great Britain, which would lead to a $40 \%$ increase in the overall trend in PET. So, if this effect were to be included, it would confirm the results found in this paper.

Although the contribution is generally smaller (except in Scotland), the trends in LW radiation in these datasets contribute to between 15 and $27 \%$ of the trends in PET and between 27 and $46 \%$ of the trends in the radiative component. In Scotland the downward LW radiation is the dominant driver of changing PET in the relative humidity formulation. Note, however, that this is largely cancelled by the increasing upwelling LW, which is captured in this study in the effect of air temperature on the radiative component, and which may be different if the approximation that the difference between air temperature and surface temperature is negligible were relaxed. Observations of LW radiation are often uncertain, but the trend in this dataset, although small, is consistent with observed trends (Wang and Liang, 2009), as well as with trends in the WFDEI bias-corrected reanalysis product (Weedon et al., 2014).

Trends in temperature and cloud cover in the UK are expected to continue into the coming decades, with precipitation expected to increase in the winter but decrease in the summer (Murphy et al., 2009). Therefore it is likely that AED will increase, increasing water stress in the summer when precipitation is lower and potentially affecting water resources, agriculture and biodiversity. This has been demonstrated for southern England and Wales by Rudd and Kay (2016), who calculated present and future PET using high-resolution regional climate model (RCM) output and included the effects of $\mathrm{CO}_{2}$ on stomatal opening.

The current study is concerned only with the effects of changing climate on AED and has assumed a constant bulk canopy resistance throughout. However, plants are expected to react to increased $\mathrm{CO}_{2}$ in the atmosphere by closing stomata and limiting the exchange of gases, including water (Kruijt et al., 2008), and observed changes in runoff have been attributed to this effect (Gedney et al., 2006, 2014). It is possible that the resulting change of canopy resistance could partially offset the increased atmospheric demand (Rudd and Kay, 2016) and may impact runoff (Gedney et al., 2006; Prudhomme et al., 2014), but further studies would be required to quantify this. 


\section{Conclusion}

This paper has presented a unique, high-resolution, observation-based dataset of meteorological variables and AED in Great Britain since 1961. Key trends in the meteorological variables are (i) increasing air temperature and specific humidity, consistent with global temperature trends; (ii) increasing solar radiation, particularly in the spring, consistent with changes in aerosol emissions and weather patterns in recent decades; (iii) decreasing wind speed, consistent with observations of global stilling; (iv) increasing precipitation, driven by increasing winter precipitation in Scotland; and (v) no significant trend in relative humidity overall, but decreasing relative humidity in the spring. The meteorological variables were used to evaluate AED in Great Britain via calculation of PET and PETI. It has been demonstrated that including the interception component in the calculation of PETI gives a mean estimate that is overall $8 \%$ larger than PET alone, with strong seasonality and spatial variation of the difference. PET was found to be increasing by $0.021 \pm 0.021 \mathrm{~mm} \mathrm{day}^{-1}$ decade $^{-1}$ in GB over the study period. With the interception component included, the trend in PETI is weaker $\left(0.019 \pm 0.020 \mathrm{~mm} \mathrm{day}^{-1}\right)$, and over GB is not significant at the $5 \%$ level. The trend in PET was analytically attributed to the trends in the meteorological variables, and it was found that the dominant effect was that increasing air temperature was driving increasing PET, with smaller increases from increased downward SW and LW radiation. However, the effect of temperature is largely compensated by the associated increase in specific humidity, while decreasing wind speed tended to decrease the PET. When the attribution was recast in terms of relative humidity, temperature was found to have a small effect on the trend in PET due to cancellation between the increase in the aerodynamic component and decrease in the radiative component, while the decreasing relative humidity caused PET to increase, at a similar rate to the downward SW radiation (and downward LW radiation in Scotland). The increase in PET due to these variables is mitigated by the observed Northern Hemisphere wind stilling, which causes a decrease in PET; however, the overall trend in PET is positive over the period of study.
In addition to providing meteorological data and estimates of AED for analysis, the meteorological variables provided are sufficient to run LSMs and hydrological models. The high spatial $(1 \mathrm{~km})$ and temporal (daily) resolution will allow this dataset to be used to study the effects of climate on physical and biological systems at a range of scales, from local to national.

\section{Data availability}

The data can be downloaded from the Environmental Information Platform at the Centre for Ecology \& Hydrology. The meteorological variables (CHESSmet) can be found at https://catalogue.ceh.ac.uk/ documents/80887755-1426-4dab-a4a6-250919d5020c, while the PET and PETI (CHESS-PE) can be accessed at https://catalogue.ceh.ac.uk/documents/ d329f4d6-95ba-4134-b77a-a377e0755653. 

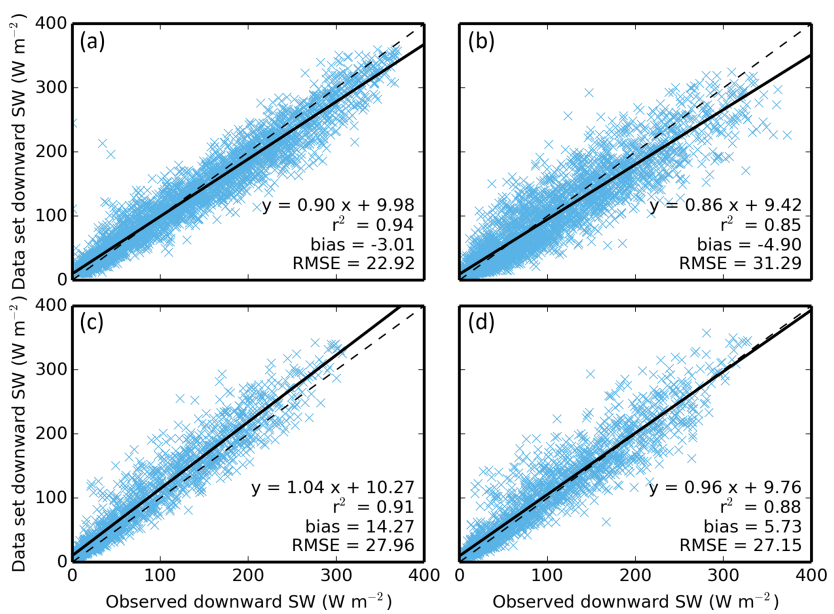

Figure A1. Plot of dataset downward SW radiation against daily mean observed downward SW radiation at four flux sites. Symbols and sites as in Fig. 4.

\section{Appendix A: Data validation}

Meteorological data were downloaded from the European Fluxes Database Cluster (http://gaia.agraria.unitus.it) for four sites positioned around Great Britain. Two were woodland sites (Alice Holt; Wilkinson et al., 2012; Heinemeyer et al., 2012 and Griffin Forest, Clement, 2003), while two had grass and crop cover (Auchencorth Moss; Billett et al., 2004 and Easter Bush; Gilmanov et al., 2007; Soussana et al., 2007). Table A1 gives details of the data used. The data are provided as half-hourly measurements, which were used to create daily means, where full daily data coverage was available. The daily means of the observed data were compared to the daily data from the grid square containing the site and the Pearson correlation $\left(r^{2}\right)$, mean bias and root mean square error (RMSE) were calculated. For each site, monthly means were calculated where the full month had available data, then a climatology calculated from available months. The same values were calculated from the relevant grid squares, using only time periods for which observed data were available.

Figure A1 shows the comparison of the dataset downward $\mathrm{SW}$ radiation against daily mean air temperature observed at the four sites. Figure A2 shows the mean monthly climatology of the daily values. The observed values of the mixing ratio of water vapour in air were compared with values calculated from the meteorological dataset, using the equation

$r_{\mathrm{w}}=q_{\mathrm{a}}\left(\frac{m_{\mathrm{a}}}{m_{\mathrm{w}}}\right)$,

where $m_{\mathrm{a}}$ is the molecular mass of dry air and $m_{\mathrm{w}}$ is the molecular mass of water. The comparisons are shown in Figs. A3 and A4.

Table A2 shows the $r^{2}$, mean bias and RMSE for each of the variables included in the validation exercise. The correlations indicate a good relationship between the dataset vari-
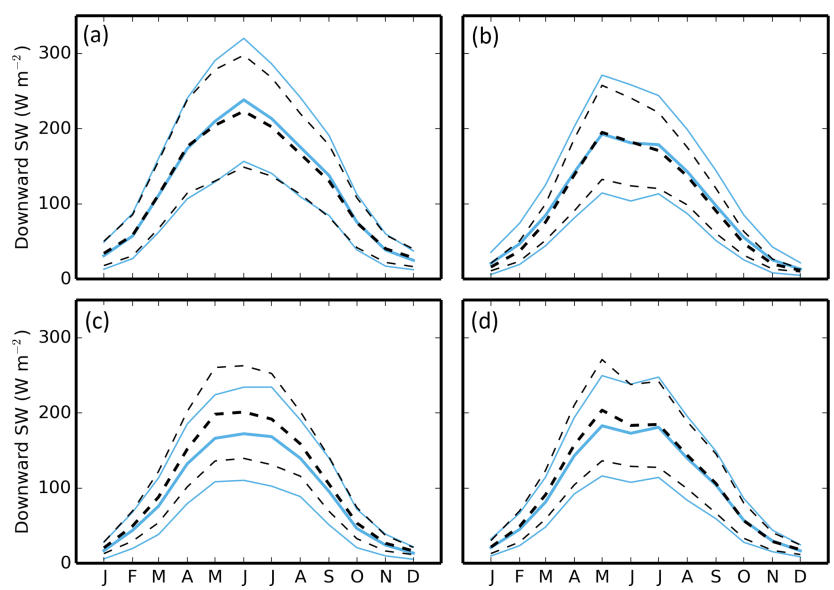

Figure A2. Mean monthly climatology of the dataset (black, dashed lines) and observed (blue, solid lines) downward SW radiation, calculated for the period of observations. Symbols as in Fig. 5, sites as in Fig. 4.
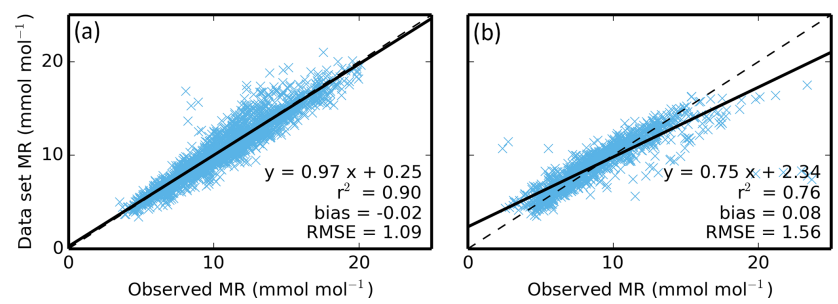

Figure A3. Plot of mixing ratio calculated using dataset meteorology against daily mean observed mixing ratio at four sites. Symbols as in Fig. 4. The sites are (a) Alice Holt and (b) Griffin Forest.
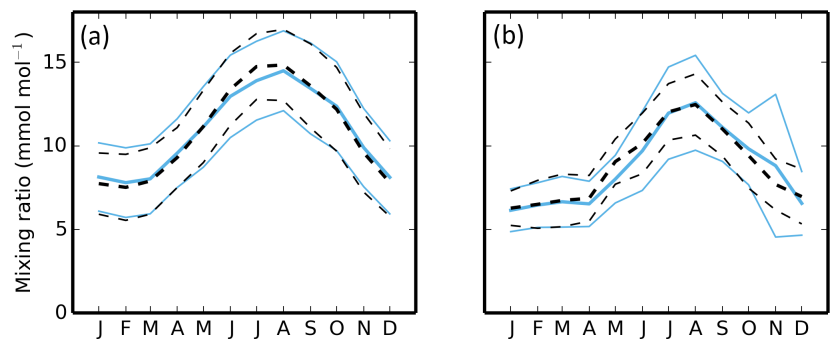

Figure A4. Mean monthly climatology of the dataset (black, dashed lines) and observed (blue, solid lines) mixing ratio, calculated for the period of observations. Symbols as in Fig. 5. Sites as in Fig. A3.

ables and the independent observations at the sites, while the mean monthly climatologies demonstrate that the data represent the seasonal cycle well. The dataset downward SW in Auchencorth Moss is biased high compared to the observations, while the wind speed is biased high at two sites. 
Table A1. Details of sites used for validation of meteorological data.

\begin{tabular}{lcccll}
\hline $\begin{array}{l}\text { Site } \\
\text { (ID) }\end{array}$ & Latitude & Longitude & Years & $\begin{array}{l}\text { Land } \\
\text { cover }\end{array}$ & Citation \\
\hline $\begin{array}{l}\text { Alice Holt } \\
\text { (UK-Ham) }\end{array}$ & 51.15 & -0.86 & $2004-2012$ & $\begin{array}{l}\text { Deciduous } \\
\text { broadleaf } \\
\text { woodland }\end{array}$ & $\begin{array}{l}\text { Wilkinson et al. (2012); } \\
\text { Heinemeyer et al. (2012) }\end{array}$ \\
\hline $\begin{array}{l}\text { Griffin Forest } \\
\text { (UK-Gri) }\end{array}$ & 56.61 & -3.80 & $1997-2001$, & $\begin{array}{l}\text { Evergreen } \\
\text { needleleaf } \\
\text { woodland }\end{array}$ & Clement (2003) \\
\hline $\begin{array}{l}\text { Auchencorth } \\
\begin{array}{l}\text { Moss } \\
\text { (UK-AMo) }\end{array}\end{array}$ & 55.79 & -3.24 & $2002-2006$ & $\begin{array}{l}\text { Grass and } \\
\text { crop }\end{array}$ & Billett et al. (2004) \\
\hline $\begin{array}{l}\text { Easter Bush } \\
\text { (UK-EBu) }\end{array}$ & 55.87 & -3.21 & $2004-2008$ & Grass & $\begin{array}{l}\text { Gilmanov et al. (2007); } \\
\text { Soussana et al. (2007) }\end{array}$ \\
\hline
\end{tabular}


Table A2. Correlation statistics for meteorological variables with data from four sites.

\begin{tabular}{|c|c|c|c|}
\hline Site & $r^{2}$ & Mean bias & RMSE \\
\hline \multicolumn{4}{|l|}{ (a) Air temperature } \\
\hline Alice Holt & 0.95 & $0.10 \mathrm{~K}$ & $1.17 \mathrm{~K}$ \\
\hline Griffin Forest & 0.94 & $0.21 \mathrm{~K}$ & $1.17 \mathrm{~K}$ \\
\hline Auchencorth Moss & 0.98 & $-0.02 \mathrm{~K}$ & $0.78 \mathrm{~K}$ \\
\hline Easter Bush & 0.97 & $-0.46 \mathrm{~K}$ & $0.96 \mathrm{~K}$ \\
\hline \multicolumn{4}{|c|}{ (b) Downward SW radiation } \\
\hline Alice Holt & 0.94 & $-3.01 \mathrm{~W} \mathrm{~m}^{-2}$ & $22.92 \mathrm{~W} \mathrm{~m}^{-2}$ \\
\hline Griffin Forest & 0.85 & $-4.90 \mathrm{~W} \mathrm{~m}^{-2}$ & $31.29 \mathrm{~W} \mathrm{~m}^{-2}$ \\
\hline Auchencorth Moss & 0.91 & $14.27 \mathrm{~W} \mathrm{~m}^{-2}$ & $27.96 \mathrm{~W} \mathrm{~m}^{-2}$ \\
\hline Easter Bush & 0.88 & $5.73 \mathrm{~W} \mathrm{~m}^{-2}$ & $27.15 \mathrm{~W} \mathrm{~m}^{-2}$ \\
\hline \multicolumn{4}{|l|}{ (c) Mixing ratio } \\
\hline Alice Holt & 0.90 & $-0.02 \mathrm{mmol} \mathrm{mol}^{-1}$ & $1.09 \mathrm{mmol} \mathrm{mol}^{-1}$ \\
\hline Griffin Forest & 0.76 & $0.08 \mathrm{mmol} \mathrm{mol}^{-1}$ & $1.56 \mathrm{mmol} \mathrm{mol}^{-1}$ \\
\hline \multicolumn{4}{|l|}{ (d) Wind speed } \\
\hline Alice Holt & 0.88 & $1.24 \mathrm{~m} \mathrm{~s}^{-1}$ & $1.45 \mathrm{~m} \mathrm{~s}^{-1}$ \\
\hline Griffin Forest & 0.59 & $1.36 \mathrm{~m} \mathrm{~s}^{-1}$ & $1.81 \mathrm{~m} \mathrm{~s}^{-1}$ \\
\hline Auchencorth Moss & 0.63 & $-0.38 \mathrm{~m} \mathrm{~s}^{-1}$ & $1.37 \mathrm{~m} \mathrm{~s}^{-1}$ \\
\hline Easter Bush & 0.82 & $0.44 \mathrm{~m} \mathrm{~s}^{-1}$ & $1.03 \mathrm{~m} \mathrm{~s}^{-1}$ \\
\hline \multicolumn{4}{|c|}{ (e) Surface air pressure } \\
\hline Griffin Forest & 0.05 & $-0.42 \mathrm{hPa}$ & $1.38 \mathrm{hPa}$ \\
\hline Auchencorth Moss & 0.01 & $-1.06 \mathrm{hPa}$ & $1.57 \mathrm{hPa}$ \\
\hline Easter Bush & 0.03 & $0.01 \mathrm{hPa}$ & $1.33 \mathrm{hPa}$ \\
\hline
\end{tabular}




\section{Appendix B: Trend maps}

Figure B1 shows the rate of change of each of the meteorological variables at the $1 \mathrm{~km}$ resolution, while Fig. B2 shows the rate of change of the PET, PETI, and the two components of PET at the same resolution. Figure B3 shows the mean relative humidity and its rate of change at the $1 \mathrm{~km}$ resolution. This shows that the regional trends are consistent with spatial variation and are not dominated by individual extreme points. 

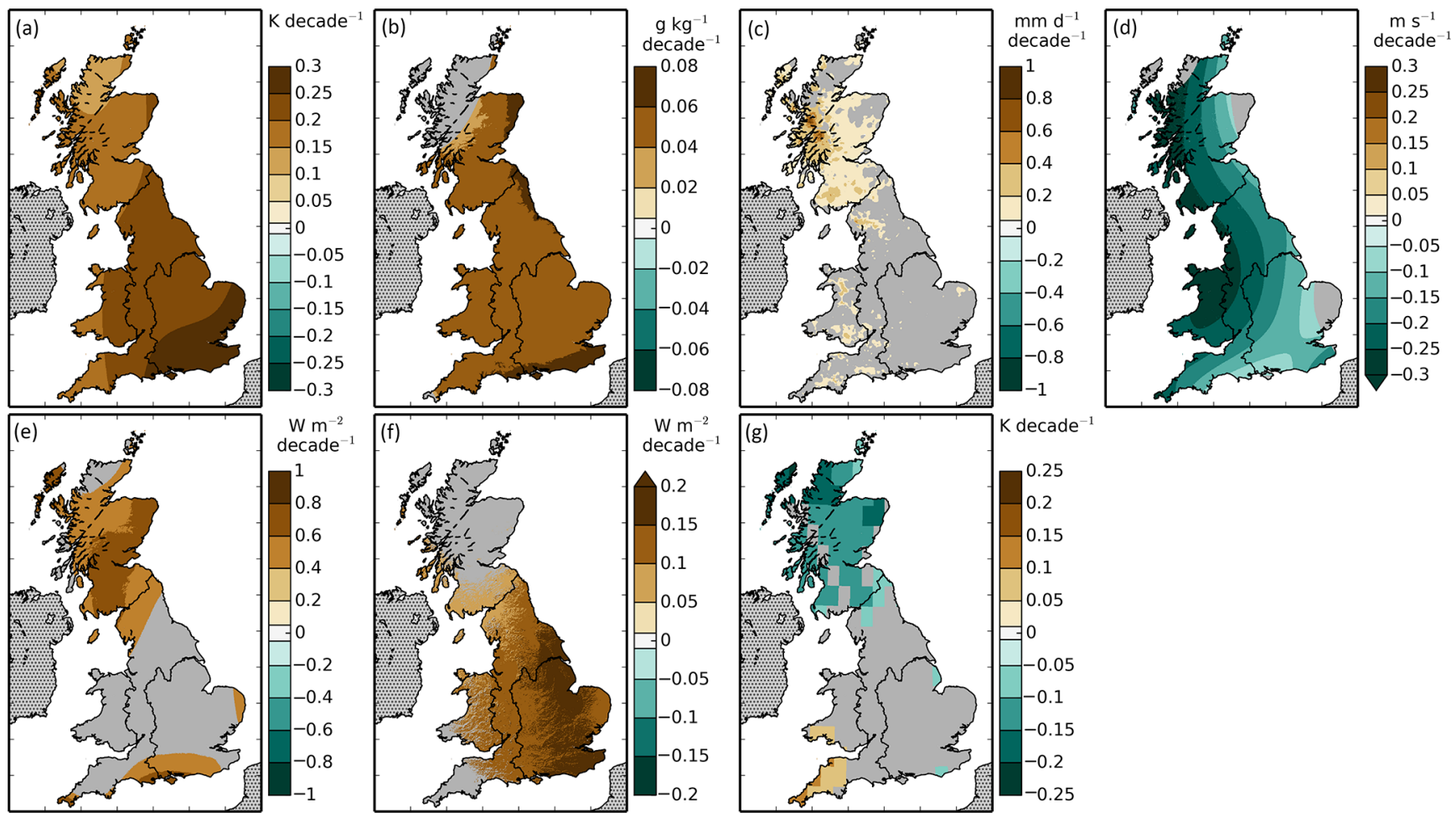

Figure B1. Rate of change of the annual means of the meteorological variables, (a) $1.2 \mathrm{~m}$ air temperature, (b) $1.2 \mathrm{~m}$ specific humidity, (c) precipitation, (d) $10 \mathrm{~m}$ wind speed, (e) downward LW radiation, (f) downward SW radiation, and (g) daily air temperature range over the period 1961-2012. Areas for which the trend was not significant are shown in grey. 

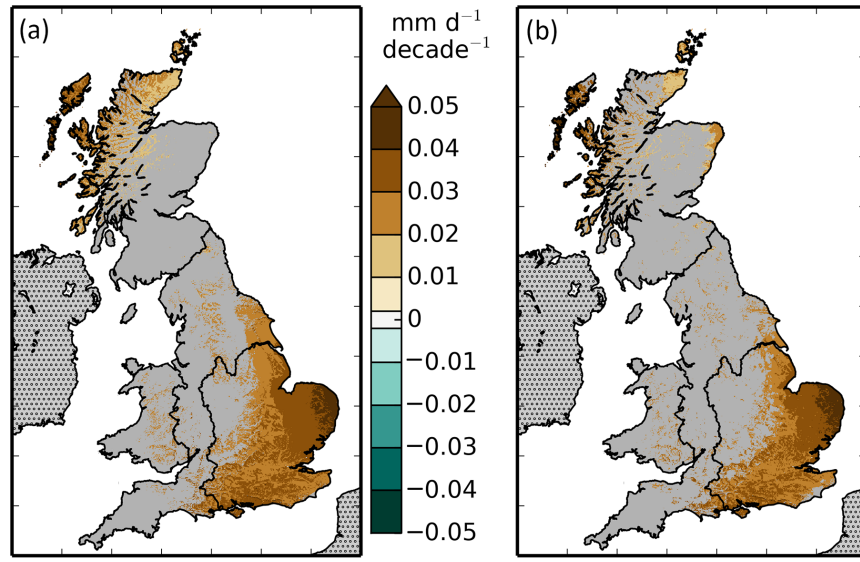

$\mathrm{mm} \mathrm{d}^{-1}$ decade $^{-1}$
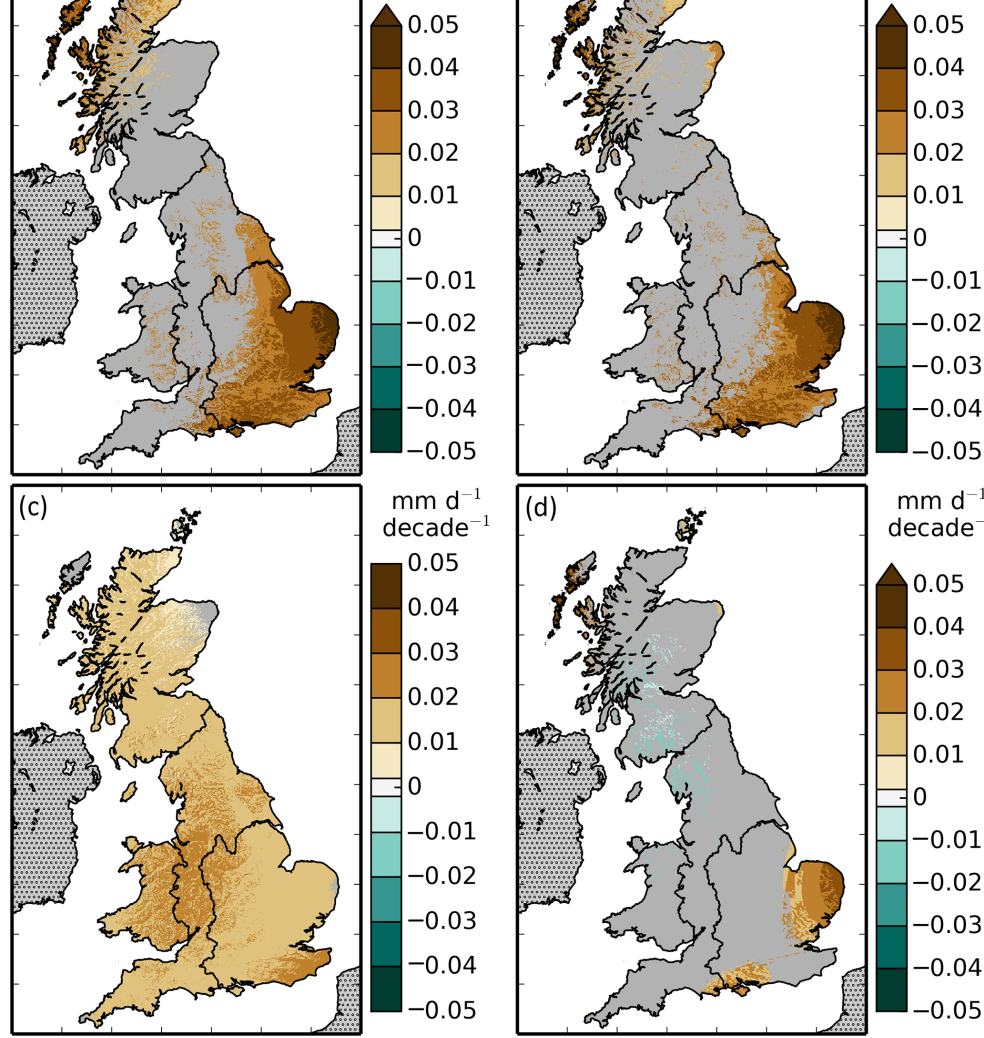

Figure B2. Rate of change the annual means of (a) PET, (b) PETI, (c) the radiative component of PET, and (d) the aerodynamic component of PET over the period 1961-2012. Areas for which the trend was not significant are shown in grey.
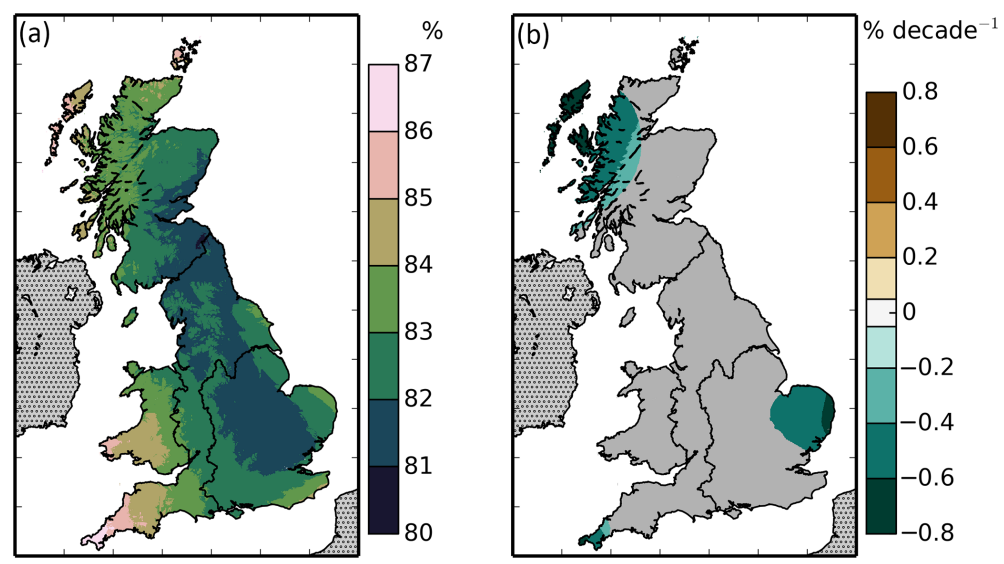

Figure B3. Maps of (a) mean and (b) rate of change of annual mean of the relative humidity over the years 1961-2012. Areas for which the trend was not significant are shown in grey. 


\section{Appendix C: Derivatives of PET}

The wind speed affects the PET through the aerodynamic resistance. The derivative with respect to wind speed is

$\frac{\partial E_{\mathrm{P}}}{\partial u_{10}}=\frac{(\Delta+\gamma) E_{\mathrm{PA}}-\gamma \frac{r_{\mathrm{s}}}{r_{\mathrm{a}}} E_{\mathrm{PR}}}{u_{10}\left(\Delta+\gamma\left(1+\frac{r_{\mathrm{s}}}{r_{\mathrm{a}}}\right)\right)}$.

The downward LW and SW radiation affect PET through the net radiation, and the derivatives are

$\frac{\partial E_{\mathrm{P}}}{\partial L_{\mathrm{d}}}=E_{\mathrm{PR}} \frac{\epsilon}{R_{\mathrm{n}}}$

$\frac{\partial E_{\mathrm{P}}}{\partial S_{\mathrm{d}}}=E_{\mathrm{PR}} \frac{(1-\alpha)}{R_{\mathrm{n}}}$.

The derivative of PET with respect to specific humidity is

$\frac{\partial E_{\mathrm{P}}}{\partial q_{\mathrm{a}}}=\frac{E_{\mathrm{PA}}}{q_{\mathrm{a}}-q_{\mathrm{s}}}$.

The air temperature affects PET through the saturated specific humidity and its derivative, the net radiation and the air density, so that the derivative of PET with respect to air temperature is

$$
\begin{aligned}
& \frac{\partial E_{\mathrm{P}}}{\partial T_{\mathrm{a}}}=E_{\mathrm{PR}}\left[\left(1-\frac{\Delta}{\Delta+\gamma\left(1+\frac{r_{\mathrm{s}}}{r_{\mathrm{a}}}\right)}\right)\right. \\
& \left(\frac{T_{\mathrm{sp}}}{T_{\mathrm{a}}^{2}} \frac{\sum_{i=1}^{4} i(i-1) a_{i} T_{\mathrm{r}}^{i-2}}{\sum_{i=1}^{4} i a_{i} T_{\mathrm{r}}^{i-1}}+\Delta \frac{p_{*}+(1-\varepsilon) e_{\mathrm{s}}}{p_{*} q_{\mathrm{s}}}-\frac{2}{T_{\mathrm{a}}}\right) \\
& \left.-\frac{4 \epsilon \sigma T_{\mathrm{a}}^{3}}{R_{\mathrm{n}}}\right]+E_{\mathrm{PA}}\left[\frac{\Delta}{q_{\mathrm{s}}-q_{\mathrm{a}}}-\frac{1}{T_{\mathrm{a}}}\right. \\
& -\frac{\Delta}{\Delta+\gamma\left(1+\frac{r_{\mathrm{s}}}{r_{\mathrm{a}}}\right)}\left(\frac{T_{\mathrm{sp}}}{T_{\mathrm{a}}^{2}} \frac{\sum_{i=1}^{4} i(i-1) a_{i} T_{\mathrm{r}}^{i-2}}{\sum_{i=1}^{4} i a_{i} T_{\mathrm{r}}^{i-1}}\right. \\
& \left.\left.+\Delta \frac{p_{*}+(1-\varepsilon) e_{\mathrm{s}}}{p_{*} q_{\mathrm{s}}}-\frac{2}{T_{\mathrm{a}}}\right)\right],
\end{aligned}
$$

where

$T_{\mathrm{r}}=1-\left(T_{\mathrm{sp}} / T_{\mathrm{a}}\right)$.

When calculating the attribution with relative humidity as the dependent variable, the derivative of PET with respect to relative humidity is

$$
\frac{\partial E_{\mathrm{P}}}{\partial \mathrm{RH}}=\frac{E_{\mathrm{PA}}}{\mathrm{RH}-1},
$$

and the derivative of PET with respect to air temperature is

$$
\begin{aligned}
& \frac{\partial E_{\mathrm{P}}}{\partial T_{\mathrm{a}}}=E_{\mathrm{PR}}\left[\left(1-\frac{\Delta}{\Delta+\gamma\left(1+\frac{r_{\mathrm{s}}}{r_{\mathrm{a}}}\right)}\right)\right. \\
& \left(\frac{\left.T_{\mathrm{sp}} \frac{\sum_{i=1}^{4} i(i-1) a_{i} T_{\mathrm{r}}^{i-2}}{T_{\mathrm{a}}^{2}}+\Delta \frac{p_{*}+(1-\varepsilon) e_{\mathrm{s}}}{p_{*} q_{\mathrm{s}}}-\frac{2}{T_{\mathrm{a}}}\right)}{\left.-\frac{4 \epsilon \sigma a_{i} T_{\mathrm{r}}^{i}}{R_{\mathrm{n}}}\right]+E_{\mathrm{PA}}\left[\frac{\Delta}{q_{\mathrm{s}}}-\frac{1}{T_{\mathrm{a}}}\right.}\right. \\
& -\frac{\Delta}{\Delta+\gamma\left(1+\frac{r_{\mathrm{s}}}{r_{\mathrm{a}}}\right)}\left(\frac{T_{\mathrm{sp}}}{T_{\mathrm{a}}^{2}} \frac{\sum_{i=1}^{4} i(i-1) a_{i} T_{\mathrm{r}}^{i-2}}{\sum_{i=1}^{4} i a_{i} T_{\mathrm{r}}^{i-1}}\right. \\
& \left.\left.+\Delta \frac{p_{*}+(1-\varepsilon) e_{\mathrm{s}}}{p_{*} q_{\mathrm{s}}}-\frac{2}{T_{\mathrm{a}}}\right)\right] .
\end{aligned}
$$

The difference between Eqs. (C8) and (C5) is the factor of $\Delta / q_{\mathrm{s}}$ instead of $\Delta /\left(q_{\mathrm{s}}-q_{\mathrm{a}}\right)$ in the second square bracket term. 
Author contributions. Eleanor M. Blyth, Jon Finch and Douglas B. Clark designed the study. Jon Finch, Alison C. Rudd, Douglas B. Clark and Emma L. Robinson developed code to create meteorological data. Emma L. Robinson created the PET and PETI. Emma L. Robinson and Eleanor M. Blyth analysed trends. Emma L. Robinson, Eleanor M. Blyth, Alison C. Rudd and Douglas B. Clark wrote the manuscript.

Competing interests. The authors declare that they have no conflict of interest.

Acknowledgements. The meteorological variables presented are based largely on GB meteorological data under licence from the Met Office, and those organisations contributing to this national dataset (including the Met Office, Environment Agency, Scottish Environment Protection Agency (SEPA) and Natural Resources Wales) are gratefully acknowledged. The CRU TS 3.21 daily temperature range data were created by the University of East Anglia Climatic Research Unit, and the WFD air pressure data were created as part of the EU FP6 project WATCH (contract 036946). Collection of flux data was funded by EU FP4 EuroFlux (Griffin Forest); EU FP5 CarboEuroFlux (Griffin Forest); EU FP5 GreenGrass (Easter Bush); EU FP6 CarboEuropeIP (Alice Holt, Griffin Forest, Auchencorth Moss, Easter Bush); EU FP6 IMECC (Griffin Forest); the Forestry Commission (Alice Holt); the Natural Environment Research Council, UK (Auchencorth Moss, Easter Bush).

Figures $1,6 \mathrm{a}$ and $\mathrm{b}$ and $\mathrm{B} 3 \mathrm{a}$ were produced with the Python implementation of the cubehelix colour scheme (Green, 2011).

Thanks to Nicola Gedney and Graham Weedon for useful discussions.

Thanks to the two anonymous reviewers and to Jack Scheff for insightful and invaluable reviewer comments.

This work was partially funded by the Natural Environment Research Council in the Changing Water Cycle programme: NERC Reference: NE/I006087/1.

Edited by: S. Schymanski

Reviewed by: J. Scheff and two anonymous referees

\section{References}

Allen, R. G., Pereira, L. S., Raes, D., and Smith, M.: Crop evapotranspiration - Guidelines for computing crop water requirements, FAO Irrigation and Drainage Paper, Food and Agriculture Organization of the United Nations, Rome, Italy, 1998.

Allen, R. G., Trezza, R., and Tasumi, M.: Analytical integrated functions for daily solar radiation on slopes, Agr. Forest Meteorol., 139, 55-73, doi:10.1016/j.agrformet.2006.05.012, 2006.

Andréassian, V., Mander, Ü., and Pae, T.: The Budyko hypothesis before Budyko: The hydrological legacy of Evald Oldekop, J. Hydrol., 535, 386-391, doi:10.1016/j.jhydrol.2016.02.002, 2016.

Ångström, A.: A study of the radiation of the atmosphere, Smithsonian Miscellaneous Collections, 65, 159-161, 1918.
Azizzadeh, M. and Javan, K.: Analyzing Trends in Reference Evapotranspiration in Northwest Part of Iran, J. Ecol. Eng., 16, 1-12, doi:10.12911/22998993/1853, 2015.

Baldocchi, D., Valentini, R., Running, S., Oechel, W., and Dahlman, R.: Strategies for measuring and modelling carbon dioxide and water vapour fluxes over terrestrial ecosystems, Global Change Biol., 2, 159-168, doi:10.1111/j.13652486.1996.tb00069.x, 1996.

Bell, V. A., Kay, A. L., Jones, R. G., Moore, R. J., and Reynard, N. S.: Use of soil data in a grid-based hydrological model to estimate spatial variation in changing flood risk across the UK, J. Hydrol., 377, 335-350, doi:10.1016/j.jhydrol.2009.08.031, 2009.

Bell, V. A., Gedney, N., Kay, A. L., Smith, R. N. B., Jones, R. G., and Moore, R. J.: Estimating Potential Evaporation from Vegetated Surfaces for Water Management Impact Assessments Using Climate Model Output, J. Hydrometeorol., 12, 1127-1136, doi:10.1175/2011jhm1379.1, 2011.

Bell, V. A., Kay, A. L., Cole, S. J., Jones, R. G., Moore, R. J., and Reynard, N. S.: How might climate change affect river flows across the Thames Basin? An area-wide analysis using the UKCP09 Regional Climate Model ensemble, J. Hydrol., 442443, 89-104, doi:10.1016/j.jhydrol.2012.04.001, 2012.

Bellamy, P. H., Loveland, P. J., Bradley, R. I., Lark, R. M., and Kirk, G. J.: Carbon losses from all soils across England and Wales 1978-2003, Nature, 437, 245-248, doi:10.1038/nature04038, 2005.

Berry, P. M., Dawson, T. P., Harrison, P. A., and Pearson, R. G.: Modelling potential impacts of climate change on the bioclimatic envelope of species in Britain and Ireland, Global Ecol. Biogeogr., 11, 453-462, doi:10.1046/j.1466-822x.2002.00304.x, 2002.

Best, M. J., Pryor, M., Clark, D. B., Rooney, G. G., Essery, R. L. H., Ménard, C. B., Edwards, J. M., Hendry, M. A., Porson, A., Gedney, N., Mercado, L. M., Sitch, S., Blyth, E., Boucher, O., Cox, P. M., Grimmond, C. S. B., and Harding, R. J.: The Joint UK Land Environment Simulator (JULES), model description Part 1: Energy and water fluxes, Geosci. Model Dev., 4, 677-699, doi:10.5194/gmd-4-677-2011, 2011.

Billett, M. F., Palmer, S. M., Hope, D., Deacon, C., StoretonWest, R., Hargreaves, K. J., Flechard, C., and Fowler, D.: Linking land-atmosphere-stream carbon fluxes in a lowland peatland system, Global Biogeochem. Cy., 18, GB1024, doi:10.1029/2003gb002058, 2004.

Bosveld, F. C. and Bouten, W.: Evaluating a Model of Evaporation and Transpiration with Observations in a Partially Wet Douglas-Fir Forest, Bound.-Lay. Meteorol., 108, 365-396, doi:10.1023/a:1024148707239, 2003.

Burch, S. F. and Ravenscroft, F.: Computer modelling of the UK wind energy resource: Final overview report, AEA Industrial Technology, Harwell, UK, 1992.

Burt, T. P. and Shahgedanova, M.: An historical record of evaporation losses since 1815 calculated using long-term observations from the Radcliffe Meteorological Station, Oxford, England, J. Hydrol., 205, 101-111, doi:10.1016/S0022-1694(97)00143-1, 1998.

Clark, D. B., Mercado, L. M., Sitch, S., Jones, C. D., Gedney, N., Best, M. J., Pryor, M., Rooney, G. G., Essery, R. L. H., Blyth, E., Boucher, O., Harding, R. J., Huntingford, C., and Cox, P. M.: The 
Joint UK Land Environment Simulator (JULES), model description - Part 2: Carbon fluxes and vegetation dynamics, Geosci. Model Dev., 4, 701-722, doi:10.5194/gmd-4-701-2011, 2011.

Clement, R., Moncrieff, J. B., and Jarvis, P. G.: Net carbon productivity of Sitka Spruce forest in Scotland, Scottish Forestry, 57, 5-10, 2003.

Cowley, J. P.: The distribution over Great Britain of global solar irradiation on a horizontal surface, Meteorol. Mag., 107, 357372, 1978.

Crane, S. B. and Hudson, J. A.: The impact of site factors and climate variability on the calculation of potential evaporation at Moel Cynnedd, Plynlimon, Hydrol. Earth Syst. Sci., 1, 429-445, doi:10.5194/hess-1-429-1997, 1997.

Crooks, S. M. and Kay, A. L.: Simulation of river flow in the Thames over 120 years: Evidence of change in rainfall-runoff response?, J. Hydrol., 4, 172-195, doi:10.1016/j.ejrh.2015.05.014, 2015.

Crooks, S. M. and Naden, P. S.: CLASSIC: a semi-distributed rainfall-runoff modelling system, Hydrol. Earth Syst. Sci., 11, 516-531, doi:10.5194/hess-11-516-2007, 2007.

Dai, A.: Recent Climatology, Variability, and Trends in Global Surface Humidity, J. Climate, 19, 3589-3606, doi:10.1175/JCLI3816.1, 2006.

Dilley, A. C. and O'Brien, D. M.: Estimating downward clear sky long-wave irradiance at the surface from screen temperature and precipitable water, Q. J. Roy. Meteorol. Soc., 124, 1391-1401, doi:10.1256/Smsqj.54902, 1998.

Donohue, R. J., McVicar, T. R., and Roderick, M. L.: Assessing the ability of potential evaporation formulations to capture the dynamics in evaporative demand within a changing climate, J. Hydrol., 386, 186-197, doi:10.1016/j.jhydrol.2010.03.020, 2010.

Doorenbos, J. and Pruitt, W. O.: Crop water requirements, FAO Irrigation and Drainage Paper 24, FAO, Rome, Italy, 1977.

Evans, N., Baierl, A., Semenov, M. A., Gladders, P., and Fitt, B. D.: Range and severity of a plant disease increased by global warming, J. Roy. Soc. Interf./Roy. Soc., 5, 525-531, doi:10.1098/rsif.2007.1136, 2008.

FAO/IIASA/ISRIC/ISS-CAS/JRC: Harmonized World Soil Database (version 1.2), FAO, Rome, Italy and IIASA, Laxenburg, Austria, 2012.

Field, M.: The meteorological office rainfall and evaporation calculation system - MORECS, Agr. Water Manage., 6, 297-306, doi:10.1016/0378-3774(83)90017-3, 1983.

Fleig, A. K., Tallaksen, L. M., James, P., Hisdal, H., and Stahl, K.: Attribution of European precipitation and temperature trends to changes in synoptic circulation, Hydrol. Earth Syst. Sci., 19, 3093-3107, doi:10.5194/hess-19-3093-2015, 2015.

Folland, C. K., Hannaford, J., Bloomfield, J. P., Kendon, M., Svensson, C., Marchant, B. P., Prior, J., and Wallace, E.: Multiannual droughts in the English Lowlands: a review of their characteristics and climate drivers in the winter half-year, Hydrol. Earth Syst. Sci., 19, 2353-2375, doi:10.5194/hess-19-23532015, 2015.

Gedney, N., Cox, P. M., Betts, R. A., Boucher, O., Huntingford, C., and Stott, P. A.: Detection of a direct carbon dioxide effect in continental river runoff records, Nature, 439, 835-838, doi:10.1038/nature04504, 2006.

Gedney, N., Huntingford, C., Weedon, G. P., Bellouin, N., Boucher, O., and Cox, P. M.: Detection of solar dimming and brightening effects on Northern Hemisphere river flow, Nat. Geosci., 7, 796800, doi:10.1038/ngeo2263, 2014.

Gill, A. E.: Atmosphere-ocean Dynamics, Academic Press, San Diego, California, USA, 1982.

Gilmanov, T. G., Soussana, J. F., Aires, L., Allard, V., Ammann, C., Balzarolo, M., Barcza, Z., Bernhofer, C., Campbell, C. L., Cernusca, A., Cescatti, A., Clifton-Brown, J., Dirks, B. O. M., Dore, S., Eugster, W., Fuhrer, J., Gimeno, C., Gruenwald, T., Haszpra, L., Hensen, A., Ibrom, A., Jacobs, A. F. G., Jones, M. B., Lanigan, G., Laurila, T., Lohila, A., Manca, G., Marcolla, B., Nagy, Z., Pilegaard, K., Pinter, K., Pio, C., Raschi, A., Rogiers, N., Sanz, M. J., Stefani, P., Sutton, M., Tuba, Z., Valentini, R., Williams, M. L., and Wohlfahrt, G.: Partitioning European grassland net ecosystem $\mathrm{CO}_{2}$ exchange into gross primary productivity and ecosystem respiration using light response function analysis, Agr. Ecosyst. Environ., 121, 93-120, doi:10.1016/j.agee.2006.12.008, 2007.

Gocic, M. and Trajkovic, S.: Analysis of trends in reference evapotranspiration data in a humid climate, Hydrolog. Sci. J., 59, 165180, doi:10.1080/02626667.2013.798659, 2013.

Gold, C. M.: Surface interpolation, spatial adjacency and GIS, in: Three Dimensional Applications in Geographical Information Systems, edited by: Raper, J., Taylor and Francis, London, 1989.

Green, D. A.: A colour scheme for the display of astronomical intensity images, B. Astron. Soc. India, 39, 289-295, 2011.

Haddeland, I., Clark, D. B., Franssen, W., Ludwig, F., Voß, F., Arnell, N. W., Bertrand, N., Best, M., Folwell, S., Gerten, D., Gomes, S., Gosling, S. N., Hagemann, S., Hanasaki, N., Harding, R., Heinke, J., Kabat, P., Koirala, S., Oki, T., Polcher, J., Stacke, T., Viterbo, P., Weedon, G. P., and Yeh, P.: Multimodel Estimate of the Global Terrestrial Water Balance: Setup and First Results, J. Hydrometeorol., 12, 869-884, doi:10.1175/2011jhm1324.1, 2011.

Hannaford, J.: Climate-driven changes in UK river flows: A review of the evidence, Prog. Phys. Geogr., 39, 29-48, doi:10.1177/0309133314536755, 2015.

Hannaford, J. and Buys, G.: Trends in seasonal river flow regimes in the UK, J. Hydrol., 475, 158-174, doi:10.1016/j.jhydrol.2012.09.044, 2012.

Harris, I., Jones, P. D., Osborn, T. J., and Lister, D. H.: Updated high-resolution grids of monthly climatic observations - the CRU TS3.10 Dataset, Int. J. Climatol., 34, 623-642, doi:10.1002/Joc.3711, 2014.

Hartmann, D. L., Klein Tank, A. M. G., Rusticucci, M., Alexander, L. V., Brönnimann, S., Charabi, Y., Dentener, F. J., Dlugokencky, E. J., Easterling, D. R., Kaplan, A., Soden, B. J., Thorne, P. W., Wild, M., and Zhai, P. M.: Observations: Atmosphere and Surface, in: Climate Change 2013: The Physical Science Basis, Contribution of Working Group I to the Fifth Assessment Report of the Intergovernmental Panel on Climate Change, edited by: Stocker, T. F., Qin, D., Plattner, G.-K., Tignor, M., Allen, S. K., Boschung, J., Nauels, A., Xia, Y., Bex, V., and Midgley, P. M., Cambridge University Press, Cambridge, UK and New York, NY, USA, 159-254, 2013.

Haslinger, K. and Bartsch, A.: Creating long-term gridded fields of reference evapotranspiration in Alpine terrain based on a recalibrated Hargreaves method, Hydrol. Earth Syst. Sci., 20, 12111223, doi:10.5194/hess-20-1211-2016, 2016. 
Heinemeyer, A., Wilkinson, M., Vargas, R., Subke, J. A., Casella, E., Morison, J. I. L., and Ineson, P.: Exploring the "overflow tap" theory: linking forest soil $\mathrm{CO}_{2}$ fluxes and individual mycorrhizosphere components to photosynthesis, Biogeosciences, 9, 79-95, doi:10.5194/bg-9-79-2012, 2012.

Held, I. M. and Soden, B. J.: Robust Responses of the Hydrological Cycle to Global Warming, J. Climate, 19, 5686-5699, doi:10.1175/jcli3990.1, 2006.

Helmes, L. and Jaenicke, R.: Atmospheric turbidity determined from sunshine records, J. Aerosol Sci., 17, 261-263, doi:10.1016/0021-8502(86)90080-7, 1986.

Hickling, R., Roy, D. B., Hill, J. K., Fox, R., and Thomas, C. D.: The distributions of a wide range of taxonomic groups are expanding polewards, Global Change Biol., 12, 450-455, doi:10.1111/j.1365-2486.2006.01116.x, 2006.

Horn, B. K. P.: Hill Shading and the Reflectance Map, IEEE Proc., 69, 14-47, doi:10.1109/Proc.1981.11918, 1981.

Hosseinzadeh Talaee, P., Shifteh Some'e, B., and Sobhan Ardakani, S.: Time trend and change point of reference evapotranspiration over Iran, Theor. Appl. Climatol., 116, 639-647, doi:10.1007/s00704-013-0978-x, 2013.

Hough, M. N. and Jones, R. J. A.: The United Kingdom Meteorological Office rainfall and evaporation calculation system: MORECS version 2.0 - an overview, Hydrol. Earth Syst. Sci., 1, 227-239, doi:10.5194/hess-1-227-1997, 1997.

IPCC: Climate Change 2013: The Physical Science Basis, in: Contribution of Working Group I to the Fifth Assessment Report of the Intergovernmental Panel on Climate Change, Cambridge University Press, Cambridge, UK and New York, NY, USA, 1535 pp., 2013.

IPCC: Climate Change 2014: Impacts, Adaptation, and Vulnerability, Part A: Global and Sectoral Aspects, in: Contribution of Working Group II to the Fifth Assessment Report of the Intergovernmental Panel on Climate Change, edited by: Field, C. B., Barros, V. R., Dokken, D. J., Mach, K. J., Mastrandrea, M. D., Bilir, T. E., Chatterjee, M., Ebi, K. L., Estrada, Y. O., Genova, R. C., Girma, B., Kissel, E. S., Levy, A. N., MacCracken, S., Mastrandrea, P. R., and White, L. L., Cambridge University Press, Cambridge, UK and New York, NY, USA, 1132 pp., 2014a.

IPCC: Climate Change 2014: Impacts, Adaptation, and Vulnerability, Part B: Regional Aspects, in: Contribution of Working Group II to the Fifth Assessment Report of the Intergovernmental Panel on Climate Change, edited by: Barros, V. R., Field, C. B., Dokken, D. J., Mastrandrea, M. D., Mach, K. J., Bilir, T. E., Chatterjee, M., Ebi, K. L., Estrada, Y. O., Genova, R. C., Girma, B., Kissel, E. S., Levy, A. N., MacCracken, S., Mastrandrea, P. R., and White, L. L., Cambridge University Press, Cambridge, UK and New York, NY, USA, 688 pp., 2014b.

Iqbal, M.: An introduction to solar radiation, Academic Press, London, 1983

Ishibashi, M. and Terashima, I.: Effects of continuous leaf wetness on photosynthesis: adverse aspects of rainfall, Plant Cell Environ., 18, 431-438, doi:10.1111/j.1365-3040.1995.tb00377.x, 1995.

Jenkins, G. J., Perry, M. C., and Prior, M. J.: The climate of the United Kingdom and recent trends, Met Office Hadley Centre, Exeter, UK, 2008.

Jhajharia, D., Dinpashoh, Y., Kahya, E., Singh, V. P., and FakheriFard, A.: Trends in reference evapotranspiration in the hu- mid region of northeast India, Hydrol. Process., 26, 421-435, doi:10.1002/hyp.8140, 2012.

Jones, P. D. and Harris, I.: CRU TS3.21: Climatic Research Unit (CRU) Time-Series (TS) Version 3.21 of High Resolution Gridded Data of Month-by-month Variation in Climate (Jan. 1901-Dec. 2012), NCAS British Atmospheric Data Centre, 2013.

Jones, P. D., Lister, D. H., Osborn, T. J., Harpham, C., Salmon, M., and Morice, C. P.: Hemispheric and large-scale landsurface air temperature variations: An extensive revision and an update to 2010, J. Geophys. Res.-Atmos., 117, D05127, doi:10.1029/2011JD017139, 2012.

Kay, A. L., Bell, V. A., Blyth, E. M., Crooks, S. M., Davies, H. N., and Reynard, N. S.: A hydrological perspective on evaporation: historical trends and future projections in Britain, J. Water Clim. Change, 4, 193-208, 2013.

Kay, A. L., Rudd, A. C., Davies, H. N., Kendon, E. J., and Jones, R. G.: Use of very high resolution climate model data for hydrological modelling: baseline performance and future flood changes, Climatic Change, 33, 193-208, doi:10.1007/s10584-015-14556, 2015.

Keller, V. D. J., Tanguy, M., Prosdocimi, I., Terry, J. A., Hitt, O., Cole, S. J., Fry, M., Morris, D. G., and Dixon, H.: CEH-GEAR: $1 \mathrm{~km}$ resolution daily and monthly areal rainfall estimates for the UK for hydrological and other applications, Earth Syst. Sci. Data, 7, 143-155, doi:10.5194/essd-7-143-2015, 2015.

Kimball, B. A., Idso, S. B., and Aase, J. K.: A Model of ThermalRadiation from Partly Cloudy and Overcast Skies, Water Resour. Res., 18, 931-936, doi:10.1029/Wr018i004p00931, 1982.

Kruijt, B., Witte, J.-P. M., Jacobs, C. M. J., and Kroon, T.: Effects of rising atmospheric $\mathrm{CO}_{2}$ on evapotranspiration and soil moisture: A practical approach for the Netherlands, J. Hydrol., 349, 257267, doi:10.1016/j.jhydrol.2007.10.052, 2008.

Kume, T., Kuraji, K., Yoshifuji, N., Morooka, T., Sawano, S., Chong, L., and Suzuki, M.: Estimation of canopy drying time after rainfall using sap flow measurements in an emergent tree in a lowland mixed-dipterocarp forest in Sarawak, Malaysia, Hydrol. Process., 20, 565-578, doi:10.1002/hyp.5924, 2006.

Li, B., Chen, F., and Guo, H.: Regional complexity in trends of potential evapotranspiration and its driving factors in the Upper Mekong River Basin, Quatern. Int., 380-381, 83-94, doi:10.1016/j.quaint.2014.12.052, 2015.

Li, Y. and Zhou, M.: Trends in Dryness Index Based on Potential Evapotranspiration and Precipitation over 19612099 in Xinjiang, China, Adv. Meteorol., 2014, 1-15, doi:10.1155/2014/548230, 2014.

Liley, J. B.: New Zealand dimming and brightening, J. Geophys. Res., 114, D00D10, doi:10.1029/2008jd011401, 2009.

Lu, X., Bai, H., and Mu, X.: Explaining the evaporation paradox in Jiangxi Province of China: Spatial distribution and temporal trends in potential evapotranspiration of Jiangxi Province from 1961 to 2013, Int. Soil Water Conserv. Res., 4, 45-51, doi:10.1016/j.iswcr.2016.02.004, 2016.

Marsh, T. and Dixon, H.: The UK water balance - how much has it changed in a warming world?, in: Proceedings of the BHS Eleventh National Symposium, Hydrology for a Changing World, 9-11 July 2012, Dundee, 1-5, doi:10.7558/bhs.2012.ns32, 2012. 
Marthews, T. R., Malhi, Y., and Iwata, H.: Calculating downward longwave radiation under clear and cloudy conditions over a tropical lowland forest site: an evaluation of model schemes for hourly data, Theor. Appl. Climatol., 107, 461-477, doi:10.1007/s00704-011-0486-9, 2011.

Matsoukas, C., Benas, N., Hatzianastassiou, N., Pavlakis, K. G., Kanakidou, M., and Vardavas, I.: Potential evaporation trends over land between 1983-2008: driven by radiative fluxes or vapour-pressure deficit?, Atmos. Chem. Phys., 11, 7601-7616, doi:10.5194/acp-11-7601-2011, 2011.

McVicar, T. R., Van Niel, T. G., Li, L. T., Roderick, M. L., Rayner, D. P., Ricciardulli, L., and Donohue, R. J.: Wind speed climatology and trends for Australia, 1975-2006: Capturing the stilling phenomenon and comparison with nearsurface reanalysis output, Geophys. Res. Lett., 35, L20403, doi:10.1029/2008GL035627, 2008.

McVicar, T. R., Roderick, M. L., Donohue, R. J., Li, L. T., Van Niel, T. G., Thomas, A., Grieser, J., Jhajharia, D., Himri, Y., Mahowald, N. M., Mescherskaya, A. V., Kruger, A. C., Rehman, S., and Dinpashoh, Y.: Global review and synthesis of trends in observed terrestrial near-surface wind speeds: Implications for evaporation, J. Hydrol., 416, 182-205, doi:10.1016/j.jhydrol.2011.10.024, 2012.

Monteith, J. L.: Evaporation and environment, in: 19th Symposia of the Society for Experimental Biology, Cambridge University Press, Cambridge, 1965.

Monteith, J. L.: Evaporation and surface temperature, Q. J. Roy. Meteorol. Soc., 107, 1-27, doi:10.1002/qj.49710745102, 1981.

Moors, E.: Water Use of Forests in the Netherlands, PhD thesis, Vrije Universiteit, Amsterdam, the Netherlands, 2012.

Morris, D. G. and Flavin, R. W.: A digital terrain model for hydrology, in: Proceedings of the 4th International Symposium on Spatial Data Handling, 23-27 July 1990, Zurich, Switzerland, 250-262, 1990.

Morton, D., Rowland, C., Wood, C., Meek, L., Marston, C., Smith, G., Wadsworth, R., and Simpson, I. C.: Final Report for LCM2007 - the new UK land cover map, CEH Project Number C03259, NERC/Centre for Ecology \& Hydrology 11/07, Wallingford, UK, 2011.

Muneer, T. and Munawwar, S.: Potential for improvement in estimation of solar diffuse irradiance, Energy Convers. Manage., 47, 68-86, doi:10.1016/j.enconman.2005.03.015, 2006.

Murphy, J. M., Sexton, D. M. H., Jenkins, G. J., Boorman, P. M., Booth, B. B. B., Brown, C. C., Clark, R. T., Collins, M., Harris, G. R., Kendon, E. J., Betts, R. A., Brown, S. J., Howard, T. P., Humphrey, K. A., McCarthy, M. P., McDonald, R. E., Stephens, A., Wallace, C., Warren, R., Wilby, R., and Wood, R. A.: UK Climate Projections Science Report: Climate change projections, Met Office Hadley Centre, Exeter, 2009.

Newton, K. and Burch, S. F.: Estimation of the UK wind energy resource using computer modelling techniques and map data, Energy Technology Support Unit, AERE Harwell, Harwell, UK, 1985.

Norton, L. R., Maskell, L. C., Smart, S. S., Dunbar, M. J., Emmett, B. A., Carey, P. D., Williams, P., Crowe, A., Chandler, K., Scott, W. A., and Wood, C. M.: Measuring stock and change in the GB countryside for policy-key findings and developments from the Countryside Survey 2007 field survey, J. Environ. Manage., 113, 117-127, doi:10.1016/j.jenvman.2012.07.030, 2012.
Oldekop, E.: Evaporation from the surface of river basins, in: Collection of the Works of Students of the Meteorological Observatory, University of Tartu-Jurjew-Dorpat, Tartu, Estonia, p. 209, 1911.

Palmer, W. C.: Meteorological Drought, Res. Paper No. 45, Dept. of Commerce, Washington, D.C., 1965.

Paltineanu, C., Chitu, E., and Mateescu, E.: New trends for reference evapotranspiration and climatic water deficit, Int. Agrophys., 26, 159-165, doi:10.2478/v10247-012-0023-9, 2012.

Parker, D. and Horton, B.: Uncertainties in central England temperature 1878-2003 and some improvements to the maximum and minimum series, Int. J. Climatol., 25, 1173-1188, doi:10.1002/joc.1190, 2005.

Penman, H. L.: Natural Evaporation from Open Water, Bare Soil and Grass, P. Roy. Soc. Lond. A, 193, 120-145, doi:10.1098/rspa.1948.0037, 1948.

Pocock, M. J., Roy, H. E., Preston, C. D., and Roy, D. B.: The Biological Records Centre in the United Kingdom: a pioneer of citizen science, Biol. J. Linnean Soc., 115, 475-493, doi:10.1111/bij.12548, 2015.

Prata, A. J.: A new long-wave formula for estimating downward clear-sky radiation at the surface, Q. J. Roy. Meteorol. Soc., 122, 1127-1151, doi:10.1002/qj.49712253306, 1996.

Prescott, J. A.: Evaporation from a water surface in relation to solar radiation, T. Roy. Soc. S. Austral., 64, 114-125, 1940.

Prudhomme, C., Giuntoli, I., Robinson, E. L., Clark, D. B., Arnell, N. W., Dankers, R., Fekete, B. M., Franssen, W., Gerten, D., Gosling, S. N., Hagemann, S., Hannah, D. M., Kim, H., Masaki, Y., Satoh, Y., Stacke, T., Wada, Y., and Wisser, D.: Hydrological droughts in the 21st century, hotspots and uncertainties from a global multimodel ensemble experiment, P. Natl. Acad. Sci. USA, 111, 3262-3267, doi:10.1073/pnas.1222473110, 2014.

Pryor, S. C., Barthelmie, R. J., Young, D. T., Takle, E. S., Arritt, R. W., Flory, D., Gutowski, W. J., Nunes, A., and Roads, J.: Wind speed trends over the contiguous United States, J. Geophys. Res.Atmos., 114, D14105, doi:10.1029/2008JD011416, 2009.

Reynolds, B., Chamberlain, P. M., Poskitt, J., Woods, C., Scott, W. A., Rowe, E. C., Robinson, D. A., Frogbrook, Z. L., Keith, A. M., Henrys, P. A., Black, H. I. J., and Emmett, B. A.: Countryside Survey: National "Soil Change" 1978-2007 for Topsoils in Great Britain - Acidity, Carbon, and Total Nitrogen Status, Vadose Zone J., 12, doi:10.2136/vzj2012.0114, 2013.

Richards, J. M.: A simple expression for the saturation vapour pressure of water in the range -50 to $140^{\circ} \mathrm{C}$, J. Phys. D, 4, L15-L18, 1971.

Robinson, E. L., Blyth, E., Clark, D. B., Finch, J., and Rudd, A. C.: Climate hydrology and ecology research support system potential evapotranspiration dataset for Great Britain (1961-2012) [CHESS-PE], NERC Environmental Information Data Centre, doi:10.5285/d329f4d6-95ba-4134-b77a-a377e0755653, 2015a.

Robinson, E. L., Blyth, E., Clark, D. B., Finch, J., and Rudd, A. C.: Climate hydrology and ecology research support system meteorology dataset for Great Britain (1961-2012) [CHESS-met], NERC Environmental Information Data Centre, doi:10.5285/80887755-1426-4dab-a4a6-250919d5020c, 2015b.

Rodda, J. C. and Marsh, T. J.: The 1975-76 Drought - a contemporary and retrospective review, NERC/Centre for Ecology \& Hydrology, Wallingford, UK, 2011. 
Roderick, M. L., Rotstayn, L. D., Farquhar, G. D., and Hobbins, M. T.: On the attribution of changing pan evaporation, Geophys. Res. Lett., 34, L17403, doi:10.1029/2007g1031166, 2007.

Rotstayn, L. D., Roderick, M. L., and Farquhar, G. D.: A simple pan-evaporation model for analysis of climate simulations: Evaluation over Australia, Geophys. Res. Lett., 33, L17715, doi:10.1029/2006g1027114, 2006.

Rudd, A. C. and Kay, A. L.: Use of very high resolution climate model data for hydrological modelling: estimation of potential evaporation, Hydrol. Res., 47, 660-670, doi:10.2166/nh.2015.028, 2016.

Rutter, A. J., Kershaw, K. A., Robins, P. C., and Morton, A. J.: A predictive model of rainfall interception in forests, 1 . Derivation of the model from observations in a plantation of Corsican pine, Agr. Meteorol., 9, 367-384, doi:10.1016/0002-1571(71)900343, 1971.

Sanchez-Lorenzo, A. and Wild, M.: Decadal variations in estimated surface solar radiation over Switzerland since the late 19th century, Atmos. Chem. Phys., 12, 8635-8644, doi:10.5194/acp-128635-2012, 2012.

Sanchez-Lorenzo, A., Calbó, J., and Martin-Vide, J.: Spatial and Temporal Trends in Sunshine Duration over Western Europe (1938-2004), J. Climate, 21, 6089-6098, doi:10.1175/2008jcli2442.1, 2008.

Sanchez-Lorenzo, A., Calbó, J., Brunetti, M., and Deser, C.: Dimming/brightening over the Iberian Peninsula: Trends in sunshine duration and cloud cover and their relations with atmospheric circulation, J. Geophys. Res., 114, D00D09, doi:10.1029/2008jd011394, 2009.

Sanchez-Romero, A., Sanchez-Lorenzo, A., Calbó, J., González, J. A., and Azorin-Molina, C.: The signal of aerosolinduced changes in sunshine duration records: A review of the evidence, J. Geophys. Res.- Atmos., 119, 4657-4673, doi:10.1002/2013JD021393, 2014.

Scheff, J. and Frierson, D. M. W.: Scaling Potential Evapotranspiration with Greenhouse Warming, J. Climate, 27, 1539-1558, doi:10.1175/JCLI-D-13-00233.1, 2014.

Schneider, T., O'Gorman, P. A., and Levine, X. J.: Water Vapor and the Dynamics of Climate Changes, Rev. Geophys., 48, RG3001, doi:10.1029/2009rg000302, 2010.

Schymanski, S. J. and Or, D.: Wind effects on leaf transpiration challenge the concept of "potential evaporation", P. Int. Assoc. Hydrol. Sci., 371, 99-107, doi:10.5194/piahs-371-99-2015, 2015.

Shan, N., Shi, Z., Yang, X., Zhang, X., Guo, H., Zhang, B., and Zhang, Z.: Trends in potential evapotranspiration from 1960 to 2013 for a desertification-prone region of China, Int. J. Climatol., 36, 3434-3445, doi:10.1002/joc.4566, 2016.

Sheffield, J., Goteti, G., and Wood, E. F.: Development of a 50Year High-Resolution Global Dataset of Meteorological Forcings for Land Surface Modeling, J. Climate, 19, 3088-3111, doi:10.1175/JCLI3790.1, 2006.

Shuttleworth, W. J.: Terrestrial Hydrometeorology, John Wiley \& Sons, Ltd, Chichester, UK, 2012.

Song, Z. W., Zhang, H. L., Snyder, R. L., Anderson, F. E., and Chen, F.: Distribution and Trends in Reference Evapotranspiration in the North China Plain, J. Irrig. Drain. Eng., 136, 240-247, doi:10.1061/(ASCE)IR.1943-4774.0000175, 2010.
Soussana, J. F., Allard, V., Pilegaard, K., Ambus, P., Amman, C., Campbell, C., Ceschia, E., Clifton-Brown, J., Czobel, S., Domingues, R., Flechard, C., Fuhrer, J., Hensen, A., Horvath, L., Jones, M., Kasper, G., Martin, C., Nagy, Z., Neftel, A., Raschi, A., Baronti, S., Rees, R. M., Skiba, U., Stefani, P., Manca, G., Sutton, M., Tuba, Z., and Valentini, R.: Full accounting of the greenhouse gas $\left(\mathrm{CO}_{2}, \mathrm{~N}_{2} \mathrm{O}, \mathrm{CH}_{4}\right)$ budget of nine $\mathrm{Eu}-$ ropean grassland sites, Agr. Ecosyst. Environ., 121, 121-134, doi:10.1016/j.agee.2006.12.022, 2007.

Stanhill, G. and Cohen, S.: Solar Radiation Changes in the United States during the Twentieth Century: Evidence from Sunshine Duration Measurements, J. Climate, 18, 1503-1512, doi:10.1175/JCLI3354.1, 2005.

Stanhill, G. and Möller, M.: Evaporative climate change in the British Isles, Int. J. Climatol., 28, 1127-1137, doi:10.1002/joc.1619, 2008.

Stewart, J. B.: On the use of the Penman-Monteith equation for determining areal evapotranspiration, in: Estimation of Areal Evapotranspiration (Proceedings of a workshop held at Vancouver, B.C., Canada, August 1987), edited by: Black, T. A. S. D. L., Novak, M. D., and Price, D. T., IAHS, Wallingford, Oxfordshire, UK, 1989.

Sutton, R. T. and Dong, B.: Atlantic Ocean influence on a shift in European climate in the 1990s, Nat. Geosci., 5, 788-792, doi:10.1038/ngeo1595, 2012.

Tabari, H., Nikbakht, J., and Hosseinzadeh Talaee, P.: Identification of Trend in Reference Evapotranspiration Series with Serial Dependence in Iran, Water Resour. Manage., 26, 2219-2232, doi:10.1007/s11269-012-0011-7, 2012.

Tanguy, M., Dixon, H., Prosdocimi, I., Morris, D. G., and Keller, V. D. J.: Gridded estimates of daily and monthly areal rainfall for the United Kingdom (1890-2012) [CEH-GEAR], NERC Environmental Information Data Centre, doi:10.5285/5dc179dcf692-49ba-9326-a6893a503f6e, 2014.

Thackeray, S. J., Sparks, T. H., Frederiksen, M., Burthe, S., Bacon, P. J., Bell, J. R., Botham, M. S., Brereton, T. M., Bright, P. W., Carvalho, L., Clutton-Brock, T., Dawson, A., Edwards, M., Elliott, J. M., Harrington, R., Johns, D., Jones, I. D., Jones, J. T., Leech, D. I., Roy, D. B., Scott, W. A., Smith, M., Smithers, R. J., Winfield, I. J., and Wanless, S.: Trophic level asynchrony in rates of phenological change for marine, freshwater and terrestrial environments, Global Change Biol., 16, 3304-3313, doi:10.1111/j.1365-2486.2010.02165.x, 2010.

Thompson, N., Barrie, I. A., and Ayles, M.: The Meteorological Office rainfall and evaporation calculation system: MORECS, Meteorological Office, Bracknell, 1981.

Vautard, R., Cattiaux, J., Yiou, P., Thepaut, J. N., and Ciais, P.: Northern Hemisphere atmospheric stilling partly attributed to an increase in surface roughness, Nat. Geosci., 3, 756-761, doi:10.1038/Ngeo979, 2010.

Vicente-Serrano, S. M., Azorin-Molina, C., Sanchez-Lorenzo, A., Revuelto, J., López-Moreno, J. I., González-Hidalgo, J. C., Moran-Tejeda, E., and Espejo, F.: Reference evapotranspiration variability and trends in Spain, 1961-2011, Global Planet. Change, 121, 26-40, doi:10.1016/j.gloplacha.2014.06.005, 2014.

Vicente-Serrano, S. M., Azorin-Molina, C., Sanchez-Lorenzo, A., El Kenawy, A., Martín-Hernández, N., Peña-Gallardo, M., Beguería, S., and Tomas-Burguera, M.: Recent changes and drivers 
of the atmospheric evaporative demand in the Canary Islands, Hydrol. Earth Syst. Sci., 20, 3393-3410, doi:10.5194/hess-203393-2016, 2016.

Vincent, L. A., Zhang, X., Brown, R. D., Feng, Y., Mekis, E., Milewska, E. J., Wan, H., and Wang, X. L.: Observed Trends in Canada's Climate and Influence of Low-Frequency Variability Modes, J. Climate, 28, 4545-4560, doi:10.1175/jcli-d-14$00697.1,2015$.

von Storch, H. and Zwiers, F. W.: Statistical analysis in climate research, Cambridge University Press, Cambridge, New York, 484 pp., 1999.

Wang, K. and Liang, S.: Global atmospheric downward longwave radiation over land surface under all-sky conditions from 1973 to 2008, J. Geophys. Res., 114, D19101, doi:10.1029/2009jd011800, 2009.

Ward, R. C. and Robinson, M.: Principles of Hydrology, McGraw Hill, London, UK, 2000.

Watts, G., Battarbee, R. W., Bloomfield, J. P., Crossman, J., Daccache, A., Durance, I., Elliott, J. A., Garner, G., Hannaford, J., Hannah, D. M., Hess, T., Jackson, C. R., Kay, A. L., Kernan, M., Knox, J., Mackay, J., Monteith, D. T., Ormerod, S. J., Rance, J., Stuart, M. E., Wade, A. J., Wade, S. D., Weatherhead, K., Whitehead, P. G., and Wilby, R. L.: Climate change and water in the UK - past changes and future prospects, Prog. Phys. Geogr., 39, 6-28, doi:10.1177/0309133314542957, 2015.

Weedon, G. P., Gomes, S., Viterbo, P., Shuttleworth, W. J., Blyth, E., Osterle, H., Adam, J. C., Bellouin, N., Boucher, O., and Best, M.: Creation of the WATCH Forcing Data and Its Use to Assess Global and Regional Reference Crop Evaporation over Land during the Twentieth Century, J. Hydrometeorol., 12, 823-848, doi:10.1175/2011jhm1369.1, 2011.

Weedon, G. P., Balsamo, G., Bellouin, N., Gomes, S., Best, M. J., and Viterbo, P.: The WFDEI meteorological forcing data set: WATCH Forcing Data methodology applied to ERAInterim reanalysis data, Water Resour. Res., 50, 7505-7514, doi:10.1002/2014WR015638, 2014.
Wild, M.: Global dimming and brightening: A review, J. Geophys. Res., 114, D00D16, doi:10.1029/2008jd011470, 2009.

Wilkinson, M., Eaton, E. L., Broadmeadow, M. S. J., and Morison, J. I. L.: Inter-annual variation of carbon uptake by a plantation oak woodland in south-eastern England, Biogeosciences, 9, 5373-5389, doi:10.5194/bg-9-5373-2012, 2012.

Willett, K. M., Dunn, R. J. H., Thorne, P. W., Bell, S., de Podesta, M., Parker, D. E., Jones, P. D., and Williams Jr., C. N.: HadISDH land surface multi-variable humidity and temperature record for climate monitoring, Clim. Past, 10, 1983-2006, doi:10.5194/cp10-1983-2014, 2014.

WMO: Manual on the Global Observing System, Secretariat of the World Meteorological Organization, Geneva, Switzerland, 2013.

Wood, C. M., Smart, S. M., and Bunce, R. G. H.: Woodland Survey of Great Britain 1971-2001, Earth Syst. Sci. Data, 7, 203-214, doi:10.5194/essd-7-203-2015, 2015.

Yin, Y., Wu, S., Chen, G., and Dai, E.: Attribution analyses of potential evapotranspiration changes in China since the 1960s, Theor. Appl. Climatol., 101, 19-28, doi:10.1007/s00704-009-0197-7, 2009.

Zhang, K.-X., Pan, S.-M., Zhang, W., Xu, Y.-H., Cao, L.-G., Hao, Y.-P., and Wang, Y.: Influence of climate change on reference evapotranspiration and aridity index and their temporal-spatial variations in the Yellow River Basin, China, from 1961 to 2012, Quatern. Int., 380-381, 75-82, doi:10.1016/j.quaint.2014.12.037, 2015.

Zhao, J., Xu, Z.-X., Zuo, D.-P., and Wang, X.-M.: Temporal variations of reference evapotranspiration and its sensitivity to meteorological factors in Heihe River Basin, China, Water Sci. Eng., 8, 1-8, doi:10.1016/j.wse.2015.01.004, 2015.

Zwiers, F. W. and von Storch, H.: Taking Serial-Correlation into Account in Tests of the Mean, J. Climate, 8, 336-351, doi:10.1175/1520-0442(1995)008<0336:Tsciai>2.0.Co;2, 1995. 